\title{
Computational Study on the Aerodynamic Performance of Wind Turbine Airfoil Fitted with Coandă Jet
}

\author{
H. Djojodihardjo, ${ }^{1,2}$ M. F. Abdul Hamid, ${ }^{2}$ A. A. Jaafar, ${ }^{3}$ S. Basri, ${ }^{3}$ F. I. Romli, ${ }^{2}$ \\ F. Mustapha, ${ }^{2}$ A. S. Mohd Rafie, ${ }^{2}$ and D. L. A. Abdul Majid ${ }^{2}$ \\ ${ }^{1}$ Universitas Al Azhar Indonesia, Kebayoran Baru, Jakarta 12110, Indonesia \\ ${ }^{2}$ Department of Aerospace Engineering, Universiti Putra Malaysia, 34400 Serdang, Selangor, Malaysia \\ ${ }^{3}$ Faculty of Manufacturing Engineering, University Malaysia Pahang, 26300 Kuantan, Pahang, Malaysia
}

Correspondence should be addressed to H. Djojodihardjo; harijono@djojodihardjo.com

Received 16 January 2013; Accepted 2 April 2013

Academic Editor: Wei-Hsin Chen

Copyright (C) 2013 H. Djojodihardjo et al. This is an open access article distributed under the Creative Commons Attribution License, which permits unrestricted use, distribution, and reproduction in any medium, provided the original work is properly cited.

\begin{abstract}
Various methods of flow control for enhanced aerodynamic performance have been developed and applied to enhance and control the behavior of aerodynamic components. The use of Coandă effect for the enhancement of circulation and lift has gained renewed interest, in particular with the progress of CFD. The present work addresses the influence, effectiveness, and configuration of Coandă-jet fitted aerodynamic surface for improving lift and $L / D$, specifically for $\$ 809$ airfoil, with a view on its incorporation in the wind turbine. A simple two-dimensional CFD modeling using $k-\varepsilon$ turbulence model is utilized to reveal the key elements that could exhibit the desired performance for a series of S809 airfoil configurations. Parametric study performed indicates that the use of Coandă-jet S809 airfoil can only be effective in certain range of trailing edge rounding-off radius, Coandă-jet thickness, and momentum jet size. The location of the Coandă-jet was found to be effective when it is placed close to the trailing edge. The results are compared with experimental data for benchmarking. Three-dimensional configurations are synthesized using certain acceptable assumptions. A trade-off study on the S809 Coandă configured airfoil is needed to judge the optimum configuration of Coandă-jet fitted Wind-Turbine design.
\end{abstract}

\section{Introduction}

In line with the efforts to enhance the use of green energy technology for energy extraction, conversion, and propulsion, the fundamental principles and mechanisms that play key roles in these technologies have been the focus in many current research efforts as well as the present research work, since these have the eventual potential of national development significance. Since one of the first attempts to generate electricity by using the wind in the United States by Charles Brush in 1888 [1], wind energy has been utilized for electricity generation using large Wind turbines in many wind farms with potential wind energy inland as well as off-shore. It has been estimated that roughly 10 million MW of energy are continuously available in the earth's wind [2]. The technical potential of onshore wind energy is very large, $20 \times 10^{9}$ to $50 \times 10^{9} \mathrm{MWh}$ per year against the current total annual world electricity consumption of about $15 \times 10^{9} \mathrm{MWh}$. The global wind power capacity installed in the year 2004 was $6614 \mathrm{MW}$, an increase in total installed generating capacity of nearly $20 \%$ from the preceding year.

Wind energy conversion research and development efforts have their origin on fluid physics, thermodynamics, and material sciences. Learning from various innovations introduced in aircraft technology, wind energy technology can take advantage of flow circulation modification and enhancement.

Flow control for enhanced aerodynamic performance has taken advantage of various techniques, such as the use of jets (continuous, synthetic, pulsed, etc.), compliant surface, vortex cell, and the like [3-16]. These active control concepts can dramatically alter the behavior of aerodynamic components 
such as airfoils, wings, and bodies. Specifically, modified circulation and enhanced circulation have been utilized for improved aircraft and land-vehicle performance as well as in novel air-vehicles lift and propulsion system concept, due to their better energy conversion capabilities [17-23]. The potential benefits of flow control include improved performance and maneuverability, affordability, increased range and payload, and environmental compliance. Active flow control may be applied to delay or advance transition, to suppress or enhance turbulence, or to prevent or promote separation, that will result in drag reduction, lift enhancement, mixing augmentation, heat transfer enhancement, and flow induced noise suppression [24], as appropriate. It could be mentioned that more recently plasma-based flow control has also been considered for wind turbine applications [25-28]. Such efforts may involve the design of "smart" wind turbine blades with integrated sensor-actuator-controller modules to improve the performance of wind turbines, by enhancing energy capture, and reduction of aerodynamic loading and noise by way of virtual aerodynamic shaping. These are beyond the scope of the present work.

In this conjunction, and with the progress of CFD, the use of Coandă effect to enhance lift has attracted renewed interest $[4-7,10-14,17,29]$. Tangential jets that take advantage of Coandă effect to closely follow the contour of the body are considered to be simple and particularly effective in that they can entrain a large mass of surrounding air. This can lead to increased circulation in the case of airfoils, or drag reduction (or drag increase if desired) in the case of bluff bodies such as an aircraft fuselage.

In the design of a novel Wind turbine using with the latest aerospace engineering technology, including aerodynamics, new lightweight materials, and efficient energy extraction technology, highly efficient aerodynamic surface came as a key issue. Recent efforts in the last decade have also indicated that Coandă effect has been given new and considerable considerations for circulation control technique $[17,19,20$, 29]. Taking advantage of these recent results, the present work looks into the effort to optimize aerodynamic performance of Wind turbine and to critically investigate the use of Coandă effect.

The progress of high speed computers exemplified by the availability of new generations of notebooks has made possible the use of first-principles-based computational approaches for the aerodynamic modeling of Wind turbine blades, to name an example. As pointed out by Xu and Sankar [17], since these approaches are based on the laws of conservation of mass, momentum, and energy, they can capture much of the physics in great detail. These approaches are particularly helpful at high wind speeds, where appreciable regions of separation are present and the flow is unsteady.

In the design of circulation control technique, one may note the progress of stall-controlled and pitch-controlled turbine rotor technology for dealing with power production at low and high wind conditions [30]. Of interest is the deployment of Wind turbines at larger range of sites not limited to a relatively small number of sites where favorable conditions exist. At the other extreme, precautions should be taken when the wind speeds become very high, when the rotor invariably stalls and experiences highly unsteady aerodynamic forces and moments. It is noted that over the past several years, there has been an increased effort to extend the usable operating range of stall-regulated Wind turbines. The concepts of circulation control through trailing edge (TE) blowing, or Coandă-jet, then came into view.

However, over the past decades, commonly used airfoil families for horizontal axis Wind turbines such as the NACA 44-, NACA 23-, NACA 63-, and NASA LS (1) series airfoils suffer noticeable performance degradation from roughness effects resulting from leading edge contamination [30]. Annual energy losses due to leading edge roughness are greatest for stall-regulated rotors. The loss is largely proportional to the reduction in maximum lift coefficient $\left(c_{l, \max }\right)$ along the blade. High blade-root twist helps reduce the loss by keeping the blade's angle of attack distribution away from stall which delays the onset of $c_{l, \max }$. Roughness also degrades the airfoil's lift-curve slope and increases the profile drag, which contributes to further losses. For stall-regulated rotors, whose angle of attack distribution increases with wind speed, the annual energy loss can be $20 \%$ to $30 \%$ where leading edge contamination from insects and airborne pollutants is common. Variable-pitch toward stall would result in similar roughness losses as fixed-pitch stall regulation, while variable-pitch toward feather would decrease the loss to around $10 \%$ at the expense of the rotor being susceptible to power spikes in turbulent high winds. For variable-rpm rotors operating at constant tip-speed ratio and angle of attack distribution, the loss is minimal at around 5\% to $10 \%$. To minimize the energy losses due to roughness effects and to develop special-purpose airfoils for horizontal axis Wind Turbine (HAWT's), the National Renewable Energy Laboratory (NREL), formerly the Solar Energy Research Institute (SERI), and the Airfoils Inc. began a joint airfoil development effort in 1984. Results of this effort have produced a new series of airfoils which are considered more appropriate for HAWT applications. These blades are providing significant increases in annual energy production as a result of less sensitivity to roughness effects, better lift-to-drag ratios, and, in the case of stall-regulated rotors, through the use of more swept area for a given generator size. Because of the economic benefits provided by these airfoils, they are recommended for retrofit blades and most new Wind turbine designs [30].

Annual energy improvements from the NREL airfoil families are projected to be $23 \%$ to $35 \%$ for stall-regulated turbines, $8 \%$ to $20 \%$ for variable-pitch turbines, and $8 \%$ to $10 \%$ for variable-rpm turbines. Optimizing airfoil's performance characteristics for the appropriate Reynolds number and thickness provides additional performance enhancement in the range of 3\% to $5 \%$ [31]. Because of the economic benefits provided by these airfoils, they are recommended for retrofit blades and most new Wind turbine designs [30]. In order to obtain results that can be well assessed, especially with reference to extensive research carried out as described in $[17,19,20,29]$, the airfoil $S 809$ [31] is considered in the present work. For this purpose, in this particular work we focus on a particular problem, that is, the basic airflow idealization over a two-dimensional airfoil in subsonic flow. Two specific conditions are considered. The first is a clean S809 airfoil and 
the second is the GTRI Dual Radius CCW airfoil that has already been investigated thoroughly, for benchmarking. The Coandă effect studies are carried out on S809 airfoil.

\section{Problem Formulation}

Circulation control wing (CCW) technology is known to be beneficial in increasing the bound circulation and hence the sectional lift coefficient of airfoil. This technology has been extensively investigated both experimentally and numerically [3-22, 29-32] over many years. Circulation control is implemented by tangentially blowing a small high-velocity jet over a highly curved surface, such as a rounded TE.

This causes the boundary layer and the jet sheet to remain attached along the curved surface due to the Coandă effect (i.e., a balance of the radial pressure gradient and centrifugal forces) causing the jet to turn without separation. The rear stagnation point location moves toward the lower airfoil surface, producing additional increase in circulation around the entire airfoil. The outer irrotational flow is also turned substantially, leading to high value of lift coefficient comparable to that achievable from conventional high lift systems, as illustrated in Figure 1(b) [4]. Tongchitpakdee et al. [19, 20] observed that early Circulation Controlled Wing designs typically had a large-radius rounded TE to maximize the lift benefit. These designs, however, also result in high drag penalty when the jet is turned off. One way to reduce this drag is to make the lower surface of the TE a flat surface, while keeping the upper surface highly curved. This curvature on the upper surface produces a large jet turning angle, leading to high lift. In this conjunction, the ability of circulation control technology to produce large values of lift advantageous for Wind turbine design since any increase in the magnitude of the lift force (while keeping drag small and $L / D$ high) will immediately contribute to a corresponding increase in induced thrust and torque will be taken into consideration.

Numerical simulation carried out by Tongchitpakdee et al. $[19,20]$ looked into two approaches of introducing Coandă-jet, that is, at the appropriately chosen point in the vicinity of the trailing as well as leading edge. A leading edge blowing jet was found to be helpful in increasing power generation at leading edge separation cases, while a TE blowing may produce the opposite effect.

With such background, the present work is aimed at the search for favorable Coandă-jet lift enhanced configuration for wind turbine designs, focusing on two-dimensional subsonic flow, by performing meticulous analysis and numerical simulation using commercially available CFD code. Results obtained from recent researches will be utilized for directing the search as well as for validation. For example, best lift enhancing configuration [19], that is, lower part of the TE surface to be flat, will be incorporated in the present numerical investigation. Case studies performed here use baseline chord dimension of $1 \mathrm{~m}$ airfoil chord length. Two values of free-stream velocities are investigated, that is, $5.77 \mathrm{~m} / \mathrm{sec}$ and $14.6 \mathrm{~m} / \mathrm{sec}$, corresponding to Reynolds number of $3.95 \times 10^{5}$ and $10^{6}$, which should fall within the typical situations for large wind turbines. The free-stream velocity in the present two-dimensional study is taken to be equal to the resultant velocity contributed by the rotation of the Wind turbine blade (at a selected baseline radial position, say $0.7 R$, with $R$ the radius of the wind turbine rotor) and the free-stream velocity of the ambient air.

\section{Objectives}

To arrive at desired design configurations, one is lead to come up with desired logical cause and effect laws as well as to find ways to carry out optimization schemes. It is with such objectives in mind that using numerical analyses, parametric studies can be carried out and may offer some clues on relevant parameters which may be utilized in a multivariable optimization (and to a larger scale, multidisciplinary optimization). The present work will investigate the influence, effectiveness, and configuration of Coandă-jet fitted aerodynamic surface, in particular S809 airfoil, for improving its lift augmentation and $L / D$, with a view on its incorporation in the design of wind turbine. In addition, parametric study is carried out for obtaining optimum configuration of the Coandă effect lift enhanced airfoil. The comprehensive results as addressed in the objective of the work will be assessed to establish key findings that will contribute to the physical basis of Coandă-jet for lift enhancement in aerodynamic lifting surfaces, and an analysis based on physical considerations will be carried out with reference to their application in propeller (or helicopter rotor) and wind turbine blade configuration for design purposes. The feasibility and practicability of Coandă configured airfoil for wind turbine applications are assessed.

\section{Computational Modeling and Salient Features of CFD Computational Scheme}

4.1. Governing Equations: Reynolds-Averaged Navier Stokes. Two-dimensional incompressible Reynolds-averaged NavierStokes (RANS) equation will be utilized to perform the analysis and to obtain numerical solutions on a computational grid surrounding a reference airfoil. The governing equation is given by (steady state and ignoring body forces)

$\underbrace{\rho \bar{u}_{j} \frac{\partial \bar{u}_{i}}{\partial x_{j}}}_{\text {Change in mean momentum of fluid element }}$

$$
\begin{gathered}
\frac{\partial}{\partial x_{j}}[\underbrace{-\bar{p} \delta_{i j}}_{\text {Normal stress }}+\overbrace{\mu\left(\frac{\partial \bar{u}_{i}}{\partial x_{j}}+\frac{\partial \bar{u}_{j}}{\partial x_{i}}\right)}^{\text {Viscous stress }}-\underbrace{\rho \overline{u_{i}^{\prime} u_{j}^{\prime}}}_{\text {Reynolds stress }}], \\
\frac{\partial \bar{u}_{i}}{\partial x_{i}}=0 .
\end{gathered}
$$

Computational fluid dynamics codes will be used to analyze the flow around two-dimensional airfoil. Various CFD codes are available and are alternatively utilized. Careful review and analysis of the application of the first principle in 

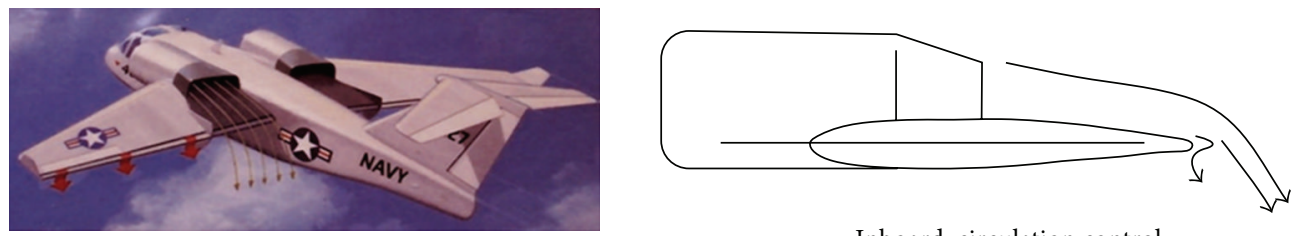

Inboard: circulation control wing/thrust deflector

(a)

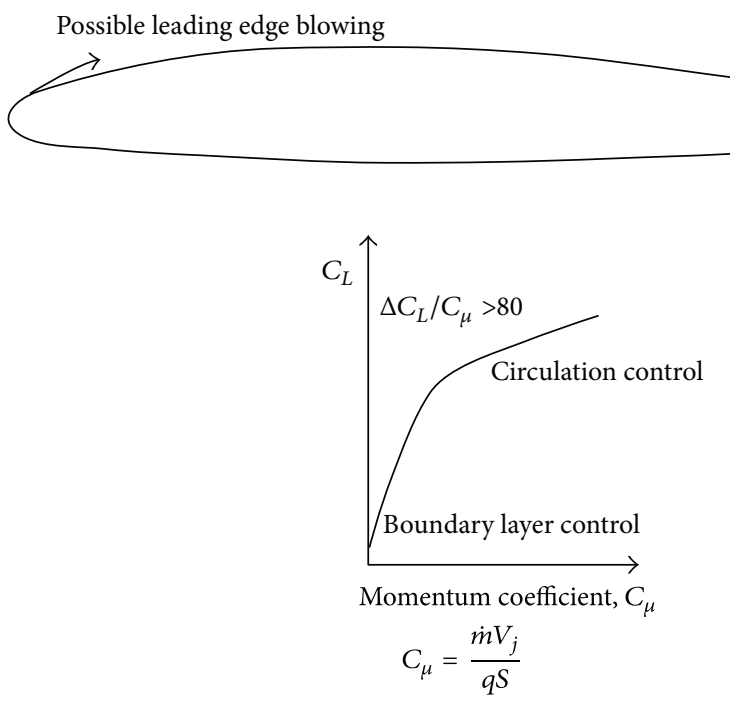

Tangential blowing over rounded trailing edge surface

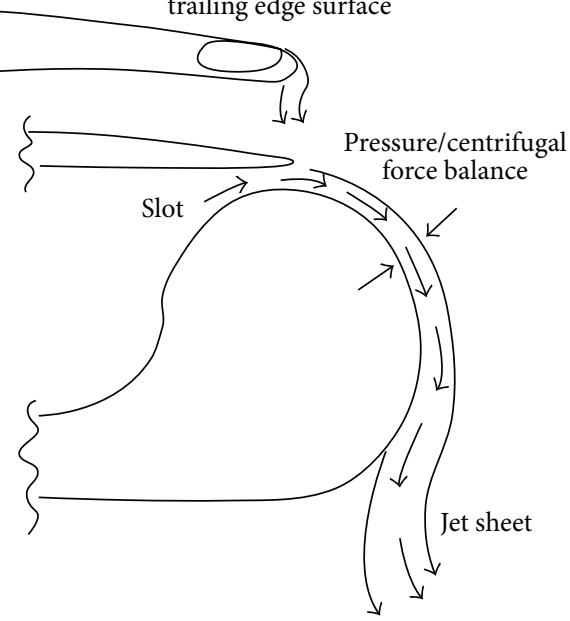

(b)

FIGURE 1: (a) Circulation control wing/upper surface blowing STOL aircraft configuration, from [4]; (b) Coandă-jet tangential blowing over TE surface for lift enhancement, from [5].

the numerical computation are carried out prior to the utilization of commercially available CFD codes for the present study. For validation of the computational procedure, resort is made to appropriate inviscid case, and online aerodynamic codes are utilized. For a two-dimensional geometry the mesh generator partitions the subdomains into triangular or quadrilateral mesh elements [33]. Care should be exercised in the choice and generation of the computational grid, which will be elaborated subsequently. The comprehensive results as addressed in the objective of the work are assessed to establish key findings that will contribute to the physical basis of Coandă-jet for lift enhancement in aerodynamic lifting surfaces. An analysis based on physical considerations is carried out with reference to its application in wind turbine blade configuration for design purposes.

The basis of the computational approach in the present work is the two-dimensional incompressible Reynoldsaveraged Navier-Stokes (RANS) equation (1) and its implementation into the CFD equation. When pursuing further the numerical solution of dynamic fluid flow using CFD techniques, in order to arrive at accurate solution, at least two aspects should be given careful attention, with due consideration of computational uncertainties. The first is the grid generation, and the second is the turbulence modeling of the particular flow. The first is based on computational algorithm including the choice of appropriate grid; the grid fineness should be chosen to obtain efficient solution, which is a combination of computational speed and accuracy. The second is the turbulence modeling, which is based on physical modeling of real flow. Associated with turbulence modeling, the wall boundaries are the most common boundaries encountered in fluid flow problems. Turbulent flows are significantly affected by the presence of walls. The successful prediction of wall bounded turbulent flows relies on the accuracy with which the flow in the near-wall region is represented. Experiments have shown that the near-wall region can be subdivided into several layers, characterized by the value of $y^{+}$, which include the viscous sublayer where the laminar property is dominant, the fully turbulent region which consists of the turbulent logarithmic layer for a range of $y^{+}$values, and the outer layer, as schematically exhibited in Figure 2(b). The no-slip condition at stationary walls forces the mean velocity components to a zero magnitude and can also significantly affect the turbulence quantities. If the grid distribution is fine enough so as to satisfy the no-slip condition, near-wall treatment is not necessary [34-42].

4.2. Turbulence Modeling Considerations. Turbulence modeling in CFD is very essential in the choice of grid fineness and obtaining the correct simulation of particular flow field. For this purpose, one has to choose a particular model out of a host of available turbulence models developed to date. One of 


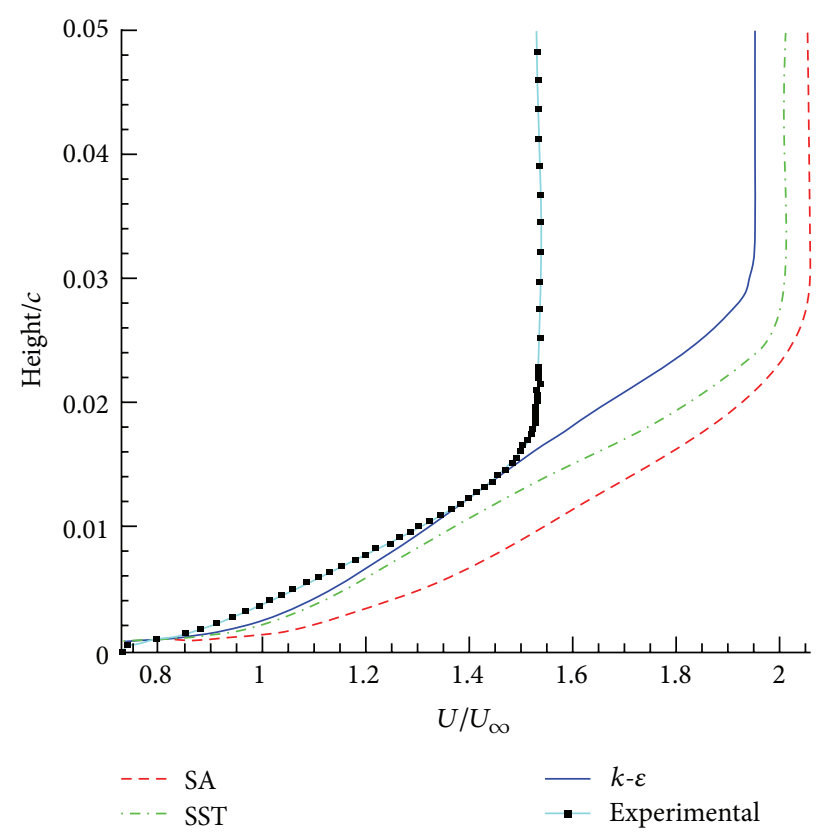

FIgURE 2: Typical $y^{+}$values in the turbulent boundary layer and velocity profiles in wall units for subsonic flow over flat plate, $M=$ $0.2, \operatorname{Re}=1 \times 10^{6}$, medium grid; nozzle pressure ratio $=1.4$. (Source: Menter [23], Salim and Cheah [45], and Economon and Milholen II [46]).

these turbulence models that is considered to be appropriate and user friendly is the $k-\varepsilon$ turbulence model, without disregarding other models that may be suitable for the purpose of the present work.

The $k$-epsilon turbulence model was first proposed by Harlow and Nakayama [34] and further developed by Jones and Launder [40]. Continuing extensive research has been carried out to understand the nature of turbulence, and this theory has been further elaborated and many other theories have also been introduced such as elaborated in [43], which seem to be satisfactory for only certain classes of cases. The turbulent viscosity models based on Reynolds-averaged Navier-Stokes (RANS) equations (1) are commonly employed in CFD codes due to their relative affordability [44]. However, since the choice of turbulence model and associated physical phenomena addressed are relevant in modeling and computer simulation of the flow situation near the airfoil surface considered here, a closer look at turbulence models utilized by the CFD code chosen will be made. Although the practical implementation of turbulence model, especially, for the nearwall treatment, has been some somewhat of a mystery [35], the numerical implementation of turbulence models has a decisive influence on the quality of simulation results. In particular, a positivity-preserving discretization of the troublesome convective terms is an important prerequisite for the robustness of the numerical algorithm [35]. The $k-\varepsilon$ model introduces two additional transport equations and two dependent variables: the turbulent kinetic energy, $k$, and the dissipation rate of turbulence energy, $\varepsilon$. Turbulent viscosity is modeled by using the Komolgorov-Prandtl expression for turbulent viscosity

$$
\mu_{\tau}=\rho \mathrm{C}_{\mu} \frac{k^{2}}{\varepsilon},
$$

where $\mathrm{C}_{\mu}$ is a model constant. In expression (2) $\mu_{\tau}$ was based on the eddy viscosity assumption introduced for convenience of further analysis by Boussinesq [41] to draw analogy between the momentum transfer caused by turbulent eddies and the viscosity in laminar flow.

The dimensionless distance in the boundary layer, sublayer scaled, representing the viscous sublayer length scale, plays significant role in capturing relevant physical turbulence phenomena near the airfoil surface commensurate with the grids utilized in the numerical computation. In this regards, the flow field in the vicinity of the airfoil surface is usually characterized by the law of the wall, which attempts to identify intricate relationships between various turbulence model scaling in various sublayers. For example, the wall functions approach (wall functions were applied at the first node from the wall) utilized by $k-\varepsilon$ turbulence model uses empirical laws to model the near-wall region [35] to circumvent the inability of the $k-\varepsilon$ model to predict a logarithmic velocity profile near a wall. The law of the wall is characterized by a dimensionless distance from the wall defined as

$$
y^{+}=\frac{u_{\tau} y}{v} .
$$

Subject to local Reynolds number considerations, the wall $y^{+}$is often used in CFD to choose the mesh fineness requirements in the numerical computation of a particular flow.

Based on preliminary attempts to choose the appropriate turbulence model which yields desirable results, in the present work, $k-\varepsilon$ turbulence model is chosen $[34,35]$. In the framework of eddy viscosity based turbulence models, the flow of a turbulent incompressible fluid is governed by the Reynolds-averaged Navier-Stokes (RANS) equation (1) for the velocity $u$ and pressure $p$.

For practical implementation purposes, it is worthwhile to introduce an auxiliary parameter $\gamma=\varepsilon / k$ to linearize the equations of the $k-\varepsilon$ turbulence model using the following equivalent representation:

$$
\begin{gathered}
\frac{\partial k}{\partial t}+\nabla \cdot\left(k u-\frac{\nu_{T}}{\sigma_{k}} \nabla k\right)+\gamma k=P_{k}, \\
\frac{\partial \varepsilon}{\partial t}+\nabla \cdot\left(\varepsilon u-\frac{\nu_{T}}{\sigma_{k}} \nabla \varepsilon\right)+C_{2} \gamma k=\gamma C_{1} P_{k} .
\end{gathered}
$$

The corresponding linearization parameter is given by $\gamma=$ $\mathrm{C}_{\mu}\left(k / \nu_{T}\right)$. Hence the standard $k-\varepsilon$ turbulence model is based on the assumption that $\nu_{T}=\mathrm{C}_{\mu}\left(k^{2} / \varepsilon\right)$, where $k$ is the turbulent kinetic energy and $\varepsilon$ is the dissipation rate. $P_{k}=$ $\left(\nu_{T} / 2\right)\left|\nabla u+\nabla u^{T}\right|^{2}$ and $\varepsilon$ are responsible for the production and dissipation of turbulent kinetic energy, respectively. The default values of the involved empirical constants are $\mathrm{C}_{\mu}=$ $0.09, C_{1}=1.44, C_{2}=1.92, \sigma_{k}=1.0$, and $\sigma_{\varepsilon}=1.3$. 
Following iterative procedure elaborated by Kuzmin et al. [35], with prescribed homogenous Neumann boundary condition and impermeable wall, it remains to prescribe the wall shear stress as well as the boundary conditions for $k$ and $\varepsilon$ on the wall. The equations of the $k-\varepsilon$ model are invalid in the vicinity of the wall, where the Reynolds number is rather low and viscous effects are dominant. Therefore, analytical solutions of the boundary layer equations are commonly employed to bridge the gap between the no-slip boundaries and the region of turbulent flow. The friction velocity $u_{\tau}$ is assumed to satisfy the nonlinear equation

$$
\frac{|u|}{u_{\tau}}=\frac{1}{\kappa} \log y^{+}+\beta
$$

valid in the logarithmic layer, where the local Reynolds number

$$
y^{+}=\frac{u_{\tau} y}{v}
$$

$\nu$ is in the range $11.06 \leq y^{+} \leq 300$. The empirical constant $\beta$ equals 5.2 for smooth walls. Note that the above derivation results in the boundary value of the turbulent eddy viscosity $\nu_{T}$ to be proportional to $\nu$. Indeed,

$$
\nu_{T}=C_{\mu} \frac{k^{2}}{\varepsilon}=\kappa u_{\tau} y=\kappa y_{*}^{+} \nu,
$$

where $y_{*}^{+}=|u| / u_{\tau}$. Based on such information, the search for appropriate grid fines, in addition to the outcome of grid fineness ratio study, is also guided by plausible comparison of the validation of CFD computational results of the test airfoil with experimental values. Here the CFD code utilized using $y^{+}$value of 11 and as suggested in [35] was found to yield satisfactory results as indicated there. Figure 2 below shows the influence of $y^{+}$in representing the boundary layer near the wall.

Various studies [23, 35, 42, 47] have indicated that integrating of the $k-\varepsilon$ type models through the near-wall region and applying the no-slip condition yield unsatisfactory results. Therefore, taking into account the need for effective choice of grid mesh compatible with the turbulence model, adopted using the commercial CFD code, a parametric study is carried out on two airfoils where either experimental data or computational results are available, to validate the computational procedure, turbulence model and grid size chosen and establish their plausibility for further application in the present work. The idea is to place the first computational nodes outside the viscous sublayer and make suitable assumptions about how the near-wall velocity profile behaves, in order to obtain the wall shear stress. Hence, the wall functions can be used to provide near-wall boundary conditions for the momentum and turbulence transport equations, rather than conditions at the wall itself, so that the viscous sublayer does not have to be resolved and the need for a very fine mesh is circumvented. The wall functions in COMSOL [48] are chosen such that the computational domain is assumed to start at a distance $y$ from the wall (see Figure 3).

By applying the wall function at the nodes of the first meshing layer of the computational grid at a distance $y$ from the wall (airfoil) surface, practically the meshing layer of width $y$ is removed from the computational domain, thus reducing the total number of grids involved, and hence reducing the computational time. Kuzmin et al. [35] have introduced a wall function that is able to control the $y^{+}$value such that the $y$ distance will not fall into the viscous sublayer, which could jeopardize the wall function assumption made. The smallest distance of $y^{+}$that can be defined, following Grotjans and Menter [47], corresponds to the point where the logarithmic layer meets the viscous sublayer.

The distance $y$ is automatically computed iteratively by solving $y^{+}=(1 / k) \log y^{+}+\beta=(1 / 0.41) \log y^{+}+5.2$, so that $y^{+}=\left(u_{\tau} y\right) / v=\rho u_{\tau}(y / \mu)$, where $u_{\tau}=\rho \mathrm{C}_{\mu}\left(k^{2} / \varepsilon\right)$ (which has been further derived by Kuzmin et al. [35] to be equivalent to $u_{\tau}=\mathrm{C}_{\mu}^{1 / 4} \sqrt{k}$ ) is the friction velocity and is equal to 11.06 . This corresponds to the distance from the wall where the logarithmic layer meets the viscous sublayer. Hence, the value of $y$, as represented by the choice of the computational grid size, can never become smaller than half of the height of the boundary mesh cell [48], as illustrated in Figure 3(a). This means that $y^{+}$can become higher than 11.06 if the mesh is relatively coarse. The $k-\varepsilon$ variables are not specified a priory, but during the computation using CFD software, $k-\varepsilon$ variable values are implicitly set to obtain acceptable $y^{+}$ values that provide relatively rapid convergence and accuracy (as validated with appropriate data).

Therefore, care is exercised in the choice of grids in the vicinity of the airfoil, to obtain a certain acceptable error tolerance (which may also be attributable to numerical error and uncertainties). The plausibility of the numerical results will be judged by comparison to other established results in the literature (numerical or experimental) for specific cases. In the present study, it was found that the turbulence intensity of $5 \%$ and length scale of $0.01 \mathrm{~m}$ yield results that agree with benchmarking data. It is noted that Howell et al. [49] also use this value and turbulence intensity of $1 \%$ in their numerical study on VAWT.

\section{Computational Set-Up and Validation}

5.1. Computational Grid. In the present work, the grids were constructed following free mesh parameter grid generation using an algebraic grid generator and varied from extremely coarse up to extremely fine grids. However, for the S809 airfoil case, near the surface of the airfoil, boundary layer based meshing is carried out throughout. Grid sensitivity study on the lift force per unit span for clean airfoil at zero angle of attack is plotted in Figure 4.

Figure 4 shows that the lift and drag are virtually insensitive of the size of the grid generated. The grid sensitivity study has led to acceptable grid sizes in the range of fine up to extra fine grid size, since within this range the lift as well as the drag forces do not change appreciably. The associated range of free mesh parameters (ranging from extra fine to fine meshing grid size) is defined in Table 1.

In order to control the $y^{+}$value (set at 11.06, on the airfoil surface), the maximum element size was set at 0.005 , while at the $\mathrm{TE}$ rounding-off surface the maximum element size was 


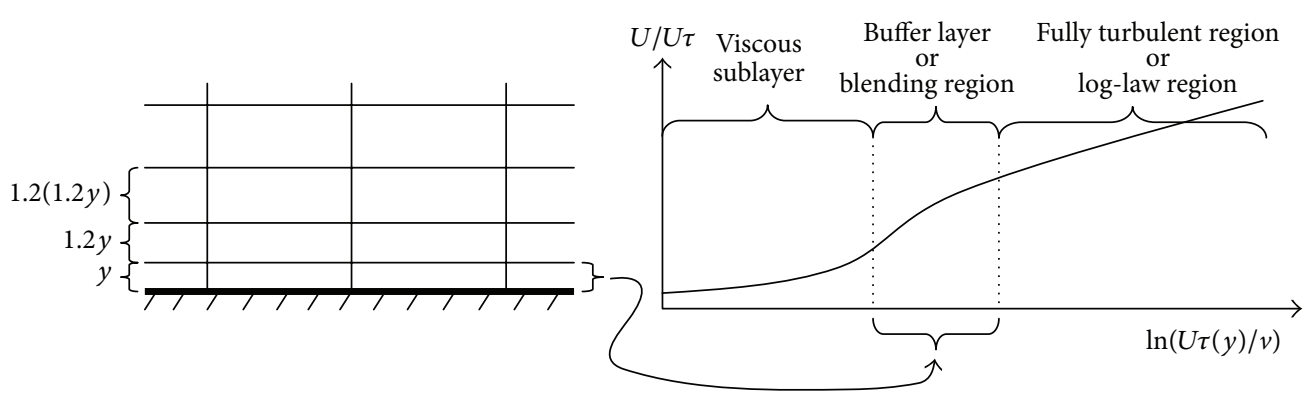

(a)

(b)

FIGURE 3: For wall functions, the computational domain starts a distance $y$ from the wall. (a) Grid generation followed from COMSOL 4.2 User's Guide; (b) the structure of turbulence boundary layer, adapted from Menter [23].

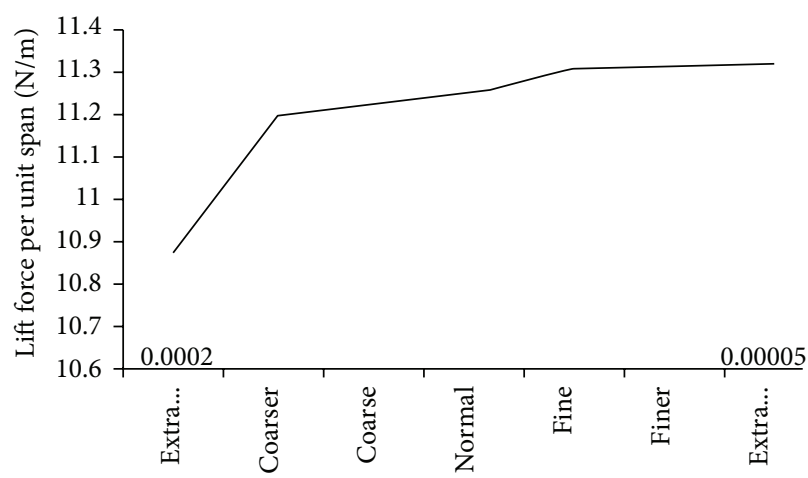

(a)

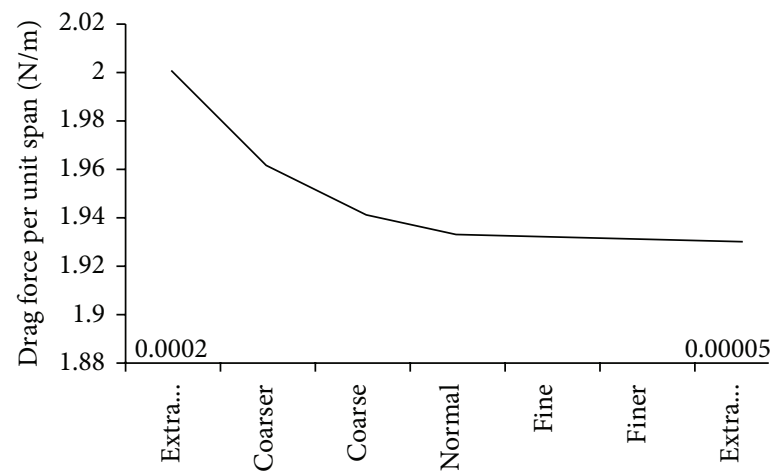

(b)

FIGURE 4: Grid sensitivity study for clean S809 airfoil at zero degree angle of attack; (a) lift force per unit span; (b) drag force per unit span.

TABLE 1: The range of free mesh parameters.

\begin{tabular}{lc}
\hline Parameter & Range \\
\hline Maximum element size & $0.156-0.42$ \\
Minimum element size & $0.018-0.12$ \\
Maximum element growth rate & $1.08-1.13$ \\
Resolution of curvature & $0.25-0.3$ \\
Resolution of narrow regions & 1 \\
\hline
\end{tabular}

set at 0.001 . At the Coandă-jet outlet, the surface is divided into a minimum of 10 grid meshes. To obtain acceptable computational results using CFD code, appropriate boundary layer mesh properties should be carefully chosen and the thin boundary layers along the no-slip boundaries should be resolved into mesh layers commensurate with the grid fineness. A boundary layer mesh is a quadrilateral mesh (2D flow) with dense element distribution in the normal direction along specific boundaries to resolve the thin boundary layers along the no-slip boundaries. The boundary layer properties chosen are defined in Table 2.

Along with the requirement of the $y^{+}$value to capture the salient turbulent flow field sublayers, a range of values of the grid dimension could be chosen to represent the thickness of the first meshing sublayers. In the present example the grid dimension was chosen to be between $0.00005 \mathrm{~m}$ and
TABLE 2: Computational grid meshing layer properties.

\begin{tabular}{lc}
\hline Parameter & Range \\
\hline Number of mesh layers in the boundary layers & 8 \\
Boundary layer mesh expansion factor & 1.2 \\
Thickness of first mesh layer & $0.00005-0.0002$ \\
Thickness adjustment factor & 1 \\
\hline
\end{tabular}

$0.0002 \mathrm{~m}$, commensurate with the curvature on the airfoil surface. Having chosen the thickness of the elements of the first meshing layer adjacent to the airfoil surface, the following consecutive layers were expanded with an expansion factor of 1.2, for eight consecutive layers. Another option can be taken to allow thickness adjustment of the first meshing layer, by choosing the thickness adjustment factor [48]; for the present study, the thickness adjustment factor of one was chosen.

The grid generator is sufficiently general so that one can easily vary the jet slot location and size. Grid spacing and clustering can have significant effects on Wind turbine load and performance predictions [49]. The outer boundary is placed far away from the blade surface, at least at six chord lengths (6C) from the airfoil surface, to avoid significant influence from outer boundary into the interior domain and to 

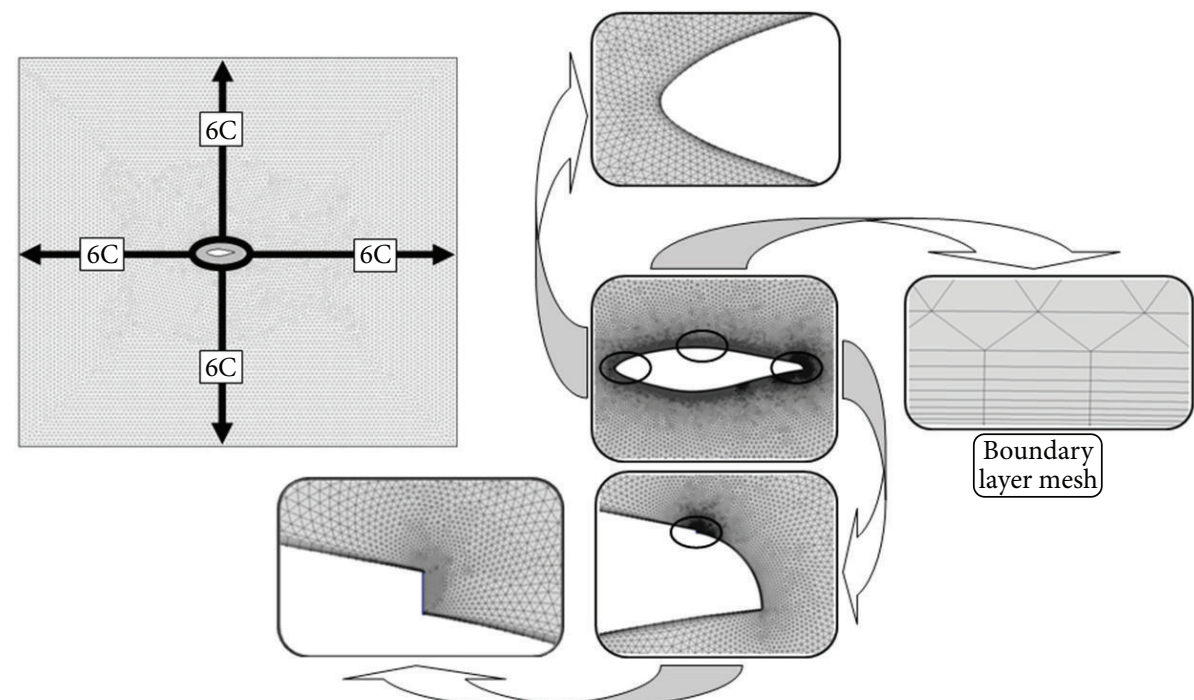

yer mesh

FIGURE 5: Computational grid around a typical airfoil, shown here for S809 Coandă configured airfoil.

allow the disturbances to leave the domain [20]. The computational domain and the grid in the vicinity of the airfoil surface and Coandă-jet slot are exhibited in Figure 5.

5.2. Initial and Boundary Conditions. In general, the initial conditions are set to be equal to the properties of the freestream flow condition [19]. The flow properties everywhere inside the flow field are assumed to be uniform and set to the free-stream values. The following initial values are used:

$$
\begin{gathered}
u=u_{\infty}, \quad v=v_{\infty}, \quad \rho=\rho_{\infty}, \quad p=p_{\infty}, \\
T=T_{\infty} .
\end{gathered}
$$

The outer boundary is placed far away from the blade surface, at a minimum of 6 chords $(6 \mathrm{C})$. Nonreflecting boundary conditions are applied at the outer boundaries of the computational domain. The jet is set to be tangential to the blade surface at the Coandă-jet nozzle location. The jet velocity profile is specified to be uniform at the jet exit. On the airfoil surface, except at the jet exit, no-slip boundary conditions are applied. To gain benefits, the jet velocity is here designed to be larger than the potential flow velocity at the vicinity of the outer edge of the boundary layer. In addition, the thickness of the Coandă-jet is designed to be less than the local boundary layer thickness.

Outer boundary conditions are chosen to minimize blockage effect, that is, significant discrepancies with free flight situations, whether theoretically or numerically simulated or experimental. Wall effects blockage changes streamline curvature interaction boundary layers and these should be minimized. The best measure is by carrying out computational experiments with reasonable outer boundaries of the computational grid and validating with both outer potential flow results and numerical parametric studies. This rationale has shown that, for the case considered, an outer grid boundary distance to the computational domain centerline of six chords produces results with high accuracy, as can be justified in the results presented in Figure 5. It should be noted, however, that Figure 5 indicates that with higher angle of attack, far-field boundaries should be placed further away from the airfoil.

5.3. Baseline Validation. Prior to its utilization, various baseline cases have been tried out, with favorable results. As a case in point, for benchmarking purposes the code has been applied to calculate the lift-slope characteristics of S809 airfoil (clean configuration, without Coandă) and GTRI CCW Dual Radius airfoil (with Coandă) and compared to the results obtained by Somers [50], as shown in Figure 6, and Englar et al. [5], as shown in Figure 7, respectively. The results as shown in both Figures demonstrated the plausibility of the present numerical computational scheme.

Computational results exhibited in Figure 6 served to validate the computational procedure associated with the use of CFD code in the numerical simulation and as a baseline in furthering the computational study of Coandă-jet in the present study. Figure 6 compares the present computational simulation using $k-\varepsilon$ turbulence model and Kuzmin's [35] wall function (the associated $y^{+}$value is 11.06) with the experimental data of Somers [50]. The numerical results above simulated similar experimental conditions of Somers for clean S809 airfoil (with wall boundary conditions and without Coandă-jet). It also shows that the lift and drag coefficients at zero angle of attack are in close agreement with the experimental data.

Similar numerical simulation was carried out for GTRI Dual Radius CCW airfoil with leading edge blowing and compared to the experimental data (in Figure 7) from Englar et al. [5] with the same boundary conditions and jet configuration using $k-\varepsilon$ turbulence model and Kuzmin's wall function [35]. Of significant interest are the grid size, the wall function, and $y^{+}$value utilized for numerical simulation. The associated $y$ value for the cells adjacent to the airfoil surface was designed to be no more than $0.0002 \mathrm{~m}$ in order to satisfy 


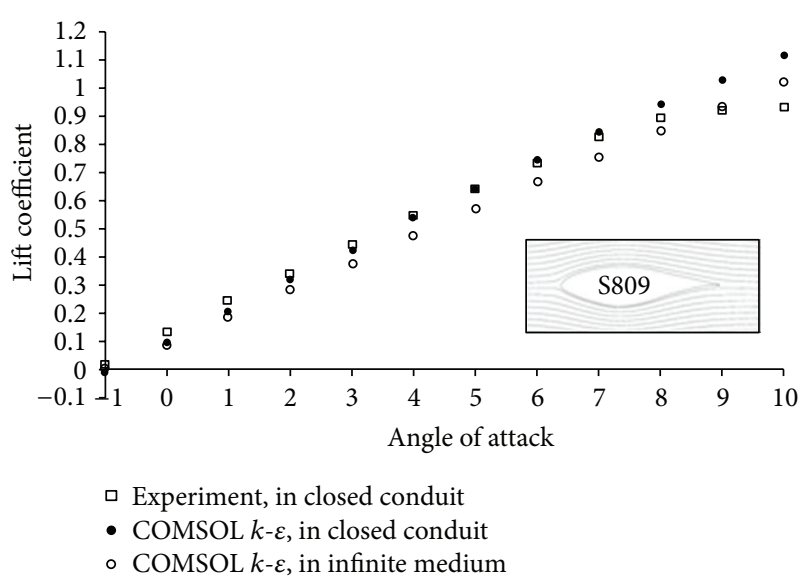

(a)

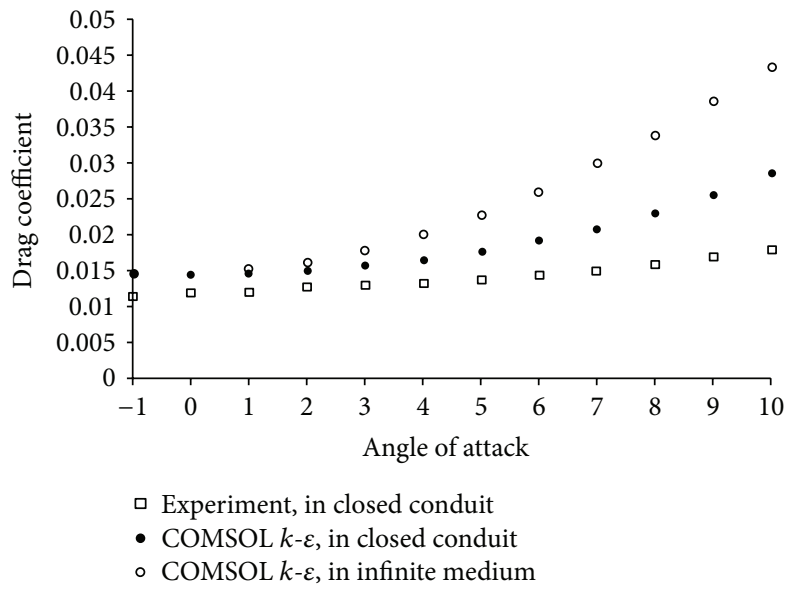

(b)

FIGURE 6: Comparison for validation of S809 airfoil of CFD computational results using COMSOL $k-\varepsilon$ turbulence model and experimental values from Somers [50] at $\mathrm{Re}=1 E 6$; (a) lift coefficient; (b) drag coefficient.

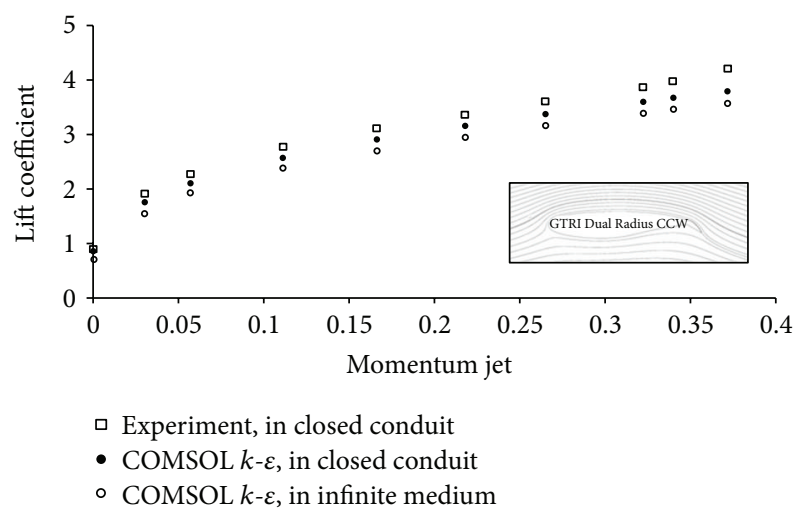

FIGURE 7: Comparison of lift-curve slope for GTRI Dual Radius CCW airfoil with LE blowing on CFD computation using COMSOL $k$ - $\varepsilon$ turbulence model and experimental values from Englar et al. [5] at $\operatorname{Re}=395,000$.

the $y^{+}$value requirements, which were chosen to be 11.06 . The results exhibited in Figure 7 for this case is also encouraging due to the close agreement between the present computation and the experimental data.

The results exhibited in both examples above serve to indicate that the computational procedure and choice of turbulence model seem to be satisfactory for the present computational study and could lend support to further use of the approach in the numerical parametric study.

All computations in the present study were performed on a laptop computer with a $2.10 \mathrm{GHz}$ Intel Core Duo processor, 4 GB of RAM, and 32-bit operating system. Typical computation time for the computation of the flow characteristics around a two dimensional airfoil is in the order of 4 hours with around 300,000 degrees of freedom by using stationary segregated solver in $k-\varepsilon$ turbulent model analysis. With such computational environment, which in consequence limits the computational grids, the present work will seek and adopt appropriate CFD numerical procedures. Simplified theoretical analysis is carried out prior to the modeling and numerical computation, while further theoretical analysis will be carried out in evaluating the computational results.

\section{Results and Discussions}

6.1. Design Considerations for Coandă Configured Airfoil. For the purpose of assessing the influence and the effectiveness of the Coandă enhanced $L / D$ and lift augmentation on wind turbine blade, a generic two-dimensional study is carried out. The problem at issue is how the Coandă-jet can be introduced at the TE of the airfoil, bearing in mind that such design may recover any losses due to the possible inception of flow separation there. In addition, for effective Coandă-jet performance, a curvature should be introduced. Furthermore, the thickness of the Coandă-jet as introduced on the airfoil surface could have a very critical effect on the intended lift enhancement function. For best effect, the lower surface near the TE should be flat, as suggested by Tongchitpakdee et al. [19, 20]. The design of the Coandăconfigured TE should also consider the off-design conditions. With all these considerations, a configuration suggested is exhibited in Figure 8.

6.2. Computational Results for S809 Airfoil. Next, we would like to investigate the influence of specifically designed airfoil geometry for Wind turbine application, and for this purpose a typical S809, in clean and Coandă-jet equipped configurations. S809 airfoil represents one of a new series of airfoils which are specifically designed for HAWT applications [20]. For the present study, the numerical simulation was carried out at two free-stream velocities. These are $5.77 \mathrm{~m} / \mathrm{s}$ (corresponding to $\operatorname{Re}=3.95 \times 10^{5}$ ) and $14.6 \mathrm{~m} / \mathrm{sec}$ (corresponding to $\operatorname{Re}=1 \times 10^{6}$ ), which represent low and high free-stream cases, respectively, while the chord-length is maintained at $c=1 \mathrm{~m}$, and density at $\rho=1.225 \mathrm{~kg} / \mathrm{m}^{3}$. The baseline for assessing 


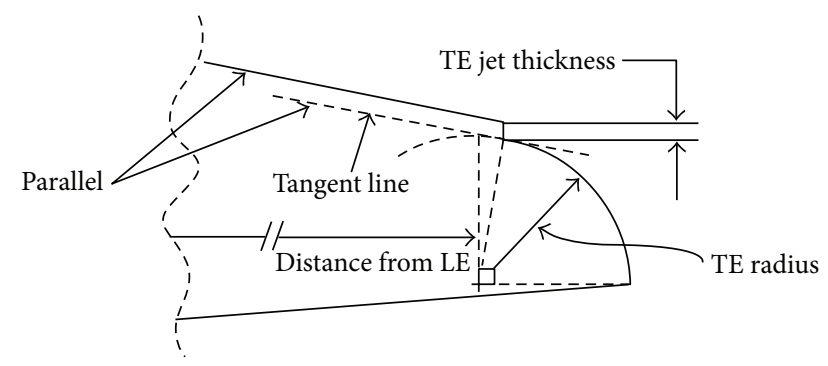

FIGURE 8: TE construction of the Coandă configured airfoil (the jet flow is tangential to the rounded circular sector).

the advantages of Coandă-jet from parametric study on S809 airfoil is the computational result for the clean airfoil. The computational result for this baseline case has been validated by comparison of the computational value for the same S809 airfoil to the experimental results based on wind-tunnel test. It should be noted that the flow field boundaries are different from those utilized for the parametric study.

The two-dimensional numerical simulation study for the S809 airfoil is carried out in logical and progressive steps. First, the numerical computation is performed on the clean S809 airfoil, then on the Coandă configured S809 airfoil without the jet (i.e., after appropriate modification due to TE rounding-off and back-step geometry), and then finally on Coandă configured S809 airfoil in its operational configuration.

To address three-dimensional wind turbine configurations, particularly for the optimum design of a horizontal axis Wind turbine (HAWT), logical adaptation should be made, taking into account the fact that different airfoil profiles may be employed at various radial sections. Certain assumptions have to be made in order to project two-dimensional simulation results to the three-dimensional case, which may be necessary to evaluate the equivalent Betz limit.

6.2.1. The Influence of Coandă-Jet on the Flow off the TE. The flow field in the vicinity of the TE for both configurations is shown in Figures 9(a) and 9(b). Careful inspection of these figures may lead to the identification of the geometry of the flow that could contribute to increased lift, in similar fashion as that contributed by flap, jet flap, or Gurney flap. Figure 9(b) typifies the flow field around Coandă configured S809 airfoil without Coandă-jet (only with its back-step configuration), which is used here to get insight to the action of the Coandăjet.

6.2.2. Parametric Study Results for Coandă Configured S809 Airfoil. The TE radius plays an important role in the Coandă configured design airfoil, since it may positively or negatively influence the downstream flow behavior. Tongchitpakdee et al. $[19,20]$ had claimed that the lower surface at the TE of the applied Coandă-jet should be flat in order to minimize the drag when the jet is turned off. Also, as reported earlier by Abramson and Rogers $[51,52]$ in the late 1980s, in spite of the ability to generate more lift the technique has not in general been applied to the production aircrafts. Many of the roadblocks have been associated with the engine bleed requirements and cruise penalties associated with blown blunt TEs. In addition, there is a tradeoff between the use of a larger radius Coandă configured airfoil for maximum lift and the use of a smaller radius one for minimum cruise drag.

In contrast to the needs of $\mathrm{TE}$ rounding-off radius, performance degradation associated with it always stands as an issue due to the drag penalty when the jet is in the off mode. To overcome such drawback, the TE radii should be specifically and carefully designed. For that purpose, simulations at several TE radius (from $10 \mathrm{~mm}$ to $50 \mathrm{~mm}$ ) have been performed, at a fixed Coandă-jet momentum coefficient $C_{\mu}$ $\left(C_{\mu}=0.003\right.$, considered just enough to fit with the Wind turbine application), and at a constant free-stream velocity of $V_{\infty}=14.6 \mathrm{~m} / \mathrm{sec}\left(\operatorname{Re}=1 \times 10^{6}\right)$, to investigate the effect of TE radius on the aerodynamic characteristics of Coandă configured airfoils. Results exhibited in Figure 10 show that a higher $L / D$ can be achieved with a smaller TE radius $(30 \mathrm{~mm})$ and that the $L / D$ is decreasing as the TE radius is increased from $30 \mathrm{~mm}$ to $50 \mathrm{~mm}$. The effect of TE radius on the lift augmentation is significant, as exhibited by the dashed line in Figure 10. However, when the TE radius is increased beyond certain value (in Figure 10, $\gg 35 \mathrm{~mm}$ ), the TE rounding-off seems to be ineffective, even detrimental.

Moving the location of the Coandă-jet forward implies the increase of the TE radius. Consequently, the camber of the airfoil will also be changed. This in turn will produce changes in the angle of attack of the airfoil compared to the baseline case. Therefore, although the present study looks into the influence of modifying TE radius, while holding other airfoil geometrical parameters constant, the zero angle of attack condition is at best possible only as first approximation. The robustness of the computational procedure adopted in the present computational set-up may be able to take into account all these changes. Such a case is indeed revealed in Figures $10(c)$ and $10(d)$ whereby the influence of all the changes of the geometrical variables accompanying the present parametric study should have been incorporated in the computational scheme which is focused on the TE radius changes and produces changes in $L$ and $D$ contributed also by the changes in the angle of attack. Additionally, these figures show that the changes in lift is much larger than the changes in drag, as exhibited in Figures 10(c) and 10(d).

Variation of the Coandă-jet thickness from $0.5 \mathrm{~mm}$ to $3.0 \mathrm{~mm}$ at a fixed $C_{\mu}\left(C_{\mu}=0.005\right)$ and at a constant freestream velocity of $V_{\infty}=14.6 \mathrm{~m} / \mathrm{sec}\left(\operatorname{Re}=1 \times 10^{6}\right)$ is performed to investigate the effect of Coandă-jet thickness (also called jet slot thickness) on the aerodynamic characteristics of Coandă configured airfoils. From Figure 11, it is found that a higher $L / D$ can be achieved with a smaller Coandă-jet thickness $(1.0 \mathrm{~mm})$ and that the $L / D$ is decreased rapidly as the Coandă-jet thickness is increased from $1.5 \mathrm{~mm}$ to $3.0 \mathrm{~mm}$. A similar behavior is observed for the lift augmentation as exhibited by the dashed line in Figure 11. However, generating a smaller jet requires higher pressure than a larger one at the same momentum coefficient. Since higher lift with as low mass flow rate as possible is preferred, a thin jet is more 


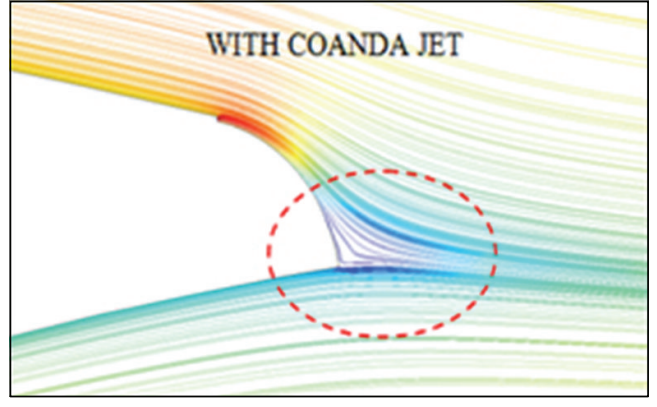

(a)

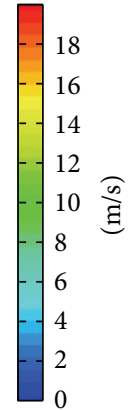

FIGURE 9: Velocity fields of S809 airfoil (a) with and (b) without Coandă-jet.

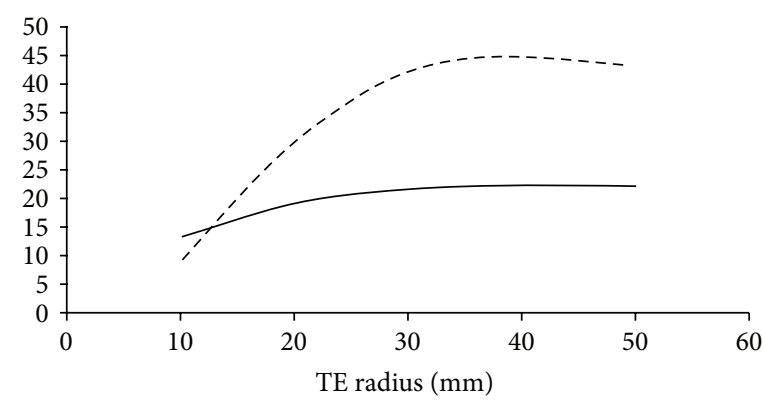

$-L / D$

- - Lift augmentation

(a)
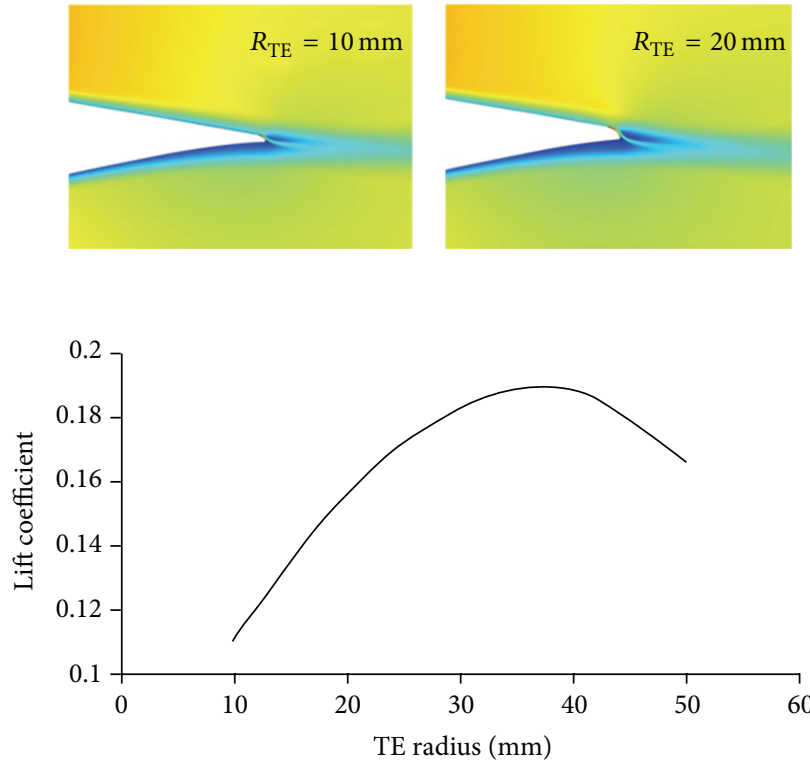

(c)
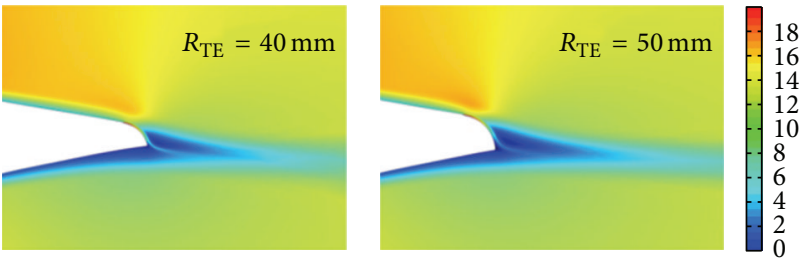

(b)

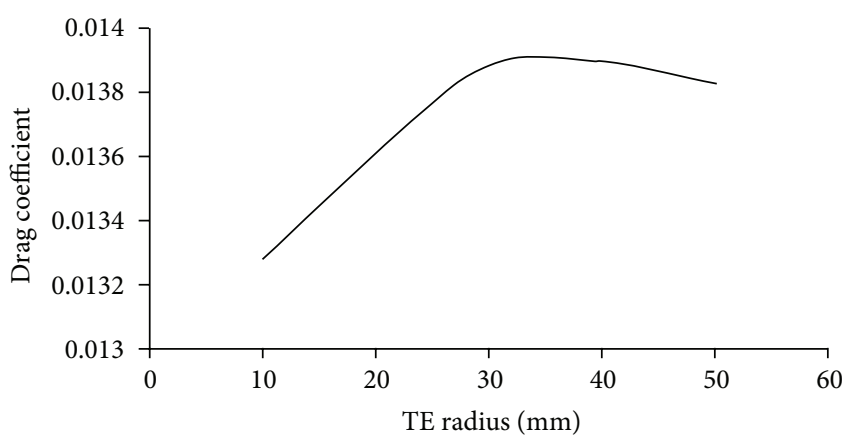

(d)

Figure 10: (a) The effect of TE radius on $L / D$ with Coandă-jet $\left(\mathrm{Re}=1 \times 10^{6}, C_{\mu}=0.005, t=1 \mathrm{~mm}\right)$; (b) velocity flow field for different TE radius; (c) lift coefficient; (d) drag coefficient.

beneficial than a thick jet [11]. From aerodynamic design perspective, within the range of agreeable power to generate Coandă-jet, a smaller Coandă-jet thickness is preferred, although further careful trade-off study should be made. Separation occurs earlier at thicker jet size compared to thinner jet size (see Figures 10(b) and 10(c)), even though both were at the same jet momentum size.

The performance of Coandă configured airfoils is dependent on the jet momentum conditions, which are important driving parameters. Figures 12(a) and 12(b) show numerical 


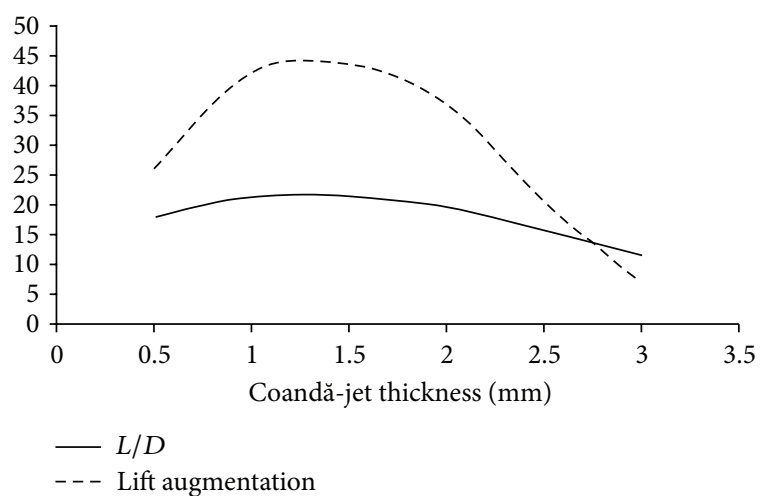

(a)

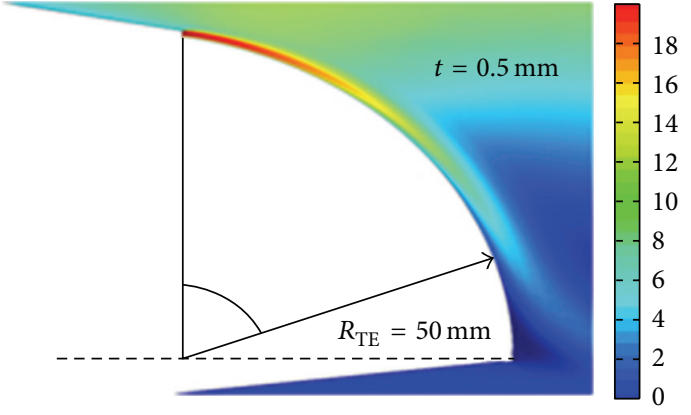

(b)

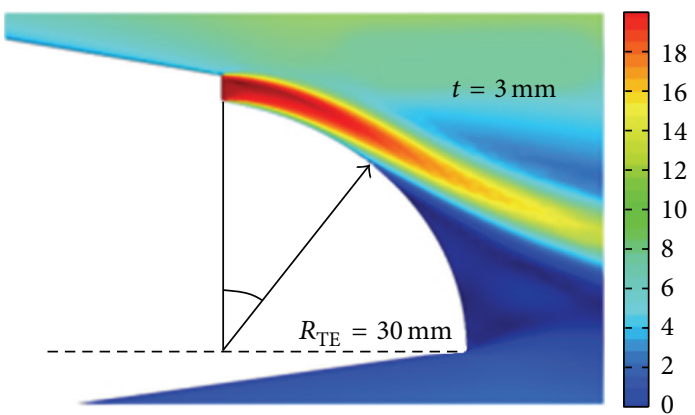

(c)

Figure 11: (a) The effect of jet thickness on the $L / D$ and lift augmentation ( $R e=1 \times 10^{6}, R_{\mathrm{TE}}=30 \mathrm{~mm}$ ); (b) flow separation with $t=0.5 \mathrm{~mm}$; (c) flow separation with $t=3.0 \mathrm{~mm}$.

simulation for a free-stream velocity of $5.77 \mathrm{~m} / \mathrm{sec}$ and $14.6 \mathrm{~m} / \mathrm{sec}$, respectively. In both free-stream velocity cases, when the jet momentum coefficient $C_{\mu} \ll 0.004$, it did not generate a sufficiently strong Coandă effect that could eliminate separation and vortex shedding, as also found in [19]. The $L / D$ increases significantly with the increase of the jet momentum coefficient $\left(C_{\mu}\right)$ until the jet momentum coefficient reaches $C_{\mu}=0.008$. After this value, the effect is otherwise. Under fixed free-stream velocity and fixed Coandă-jet thickness, the total mass flow rate increases linearly with the increase of the jet momentum. Also the jet velocity $\left(V_{\text {Coandă-jet }}\right)$ has to be increased with the mass flow rate to keep a constant $C_{\mu}$. The dotted line shown in Figures 12 (a) and 12(b) shows that the maximum lift augmentation is above 40 and 50, respectively. Figure 12(c) seems to indicate that higher free-stream velocity on the Coandă configured S809 airfoil produces higher lift, while at the same time, as exhibited in Figure 12(d), it produces lower drag.

Figure 13 also shows that the Coandă-jet is only effective when it is located at the rounding-off surface of the TE. Locating the Coandă-jet further upstream from the rounding-off surface seems to be detrimental since the Coandă-jet momentum losts its energy before reaching the end of rounding-off surface. Such notion is demonstrated in Figure 13(b) by varying the Coandă-jet nozzle at various positions upstream of the inception of the TE rounding-off surface (i.e., from $90 \%$ to $95 \%$ from the leading edge). By reaching the $\mathrm{TE}$ at the end of the rounding-off surface, the jet leaving the airfoil acts as a virtual flap.

\subsection{Contribution of Coandă-Jet Momentum Coefficient}

6.3.1. CFD Results for Coandă-Jet Configured S809 Airfoils. It should be noted that for the purposes of the present work, a uniform jet velocity profile has been adopted; this could be readily modified for more realistic modeling or design requirements. Numerical results indicate that there exists an optimum Coandă-jet configuration, which has been the subject of parametric study as exhibited in Figures 10-13 for S809 airfoil.

A significant design parameter for boundary condition, which has been utilized to characterize Coandă-jet applications by many investigators $[10,11,19,20]$, is specified by the momentum coefficient of the jet, $C_{\mu}$. For two-dimensional modeling, an equivalent jet momentum coefficient $C_{\mu}^{*}$ can be defined as

$$
C_{\mu}^{*} \equiv \frac{\dot{m} V_{\text {Coandă-jet }}}{(1 / 2) \rho V_{\infty}^{2} A_{\text {ref }}}=\frac{\rho_{\text {Coandă-jet }} V_{\text {Coandă-jet }}^{2} t_{\text {Coandă-jet }}}{(1 / 2) \rho V_{\infty}^{2} c_{\text {airfoil }}} .
$$

This expression shows that for a given constant $C_{\mu}$, changing the thickness of the Coandă-jet will affect $C_{\mu}$ favorably [53-55]. 


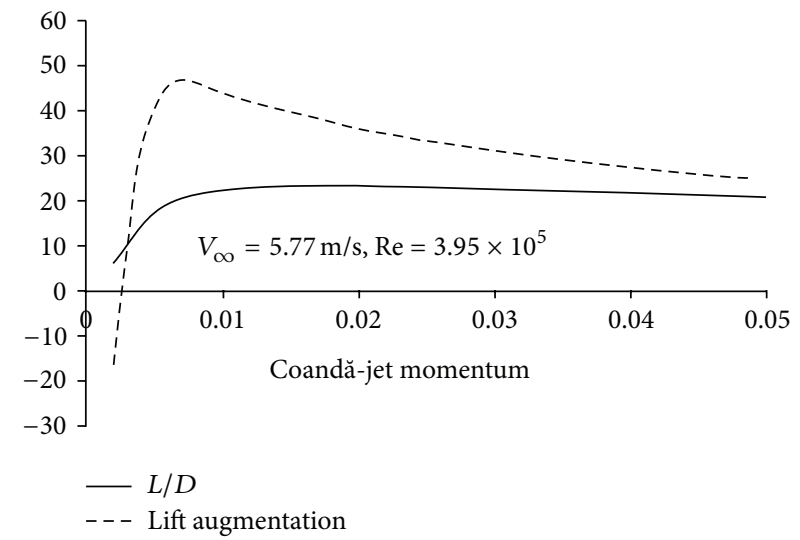

(a)

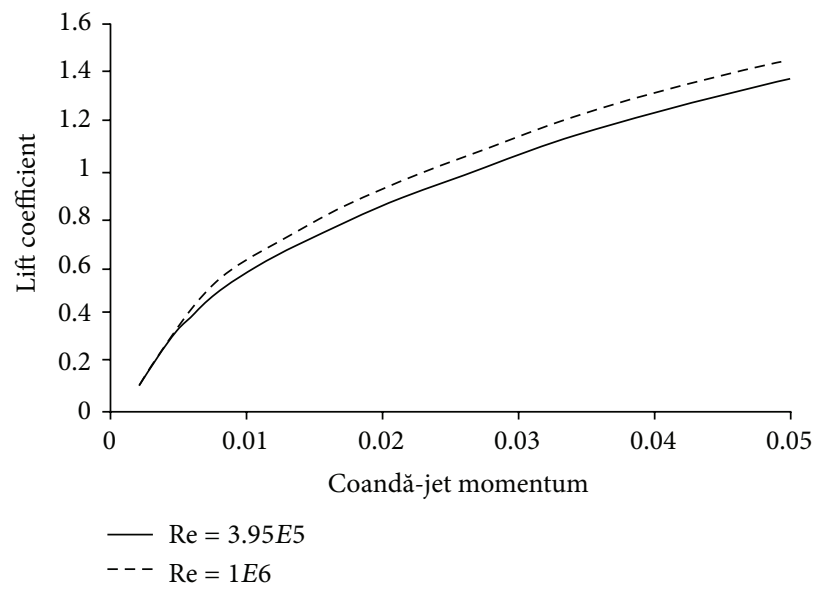

(c)

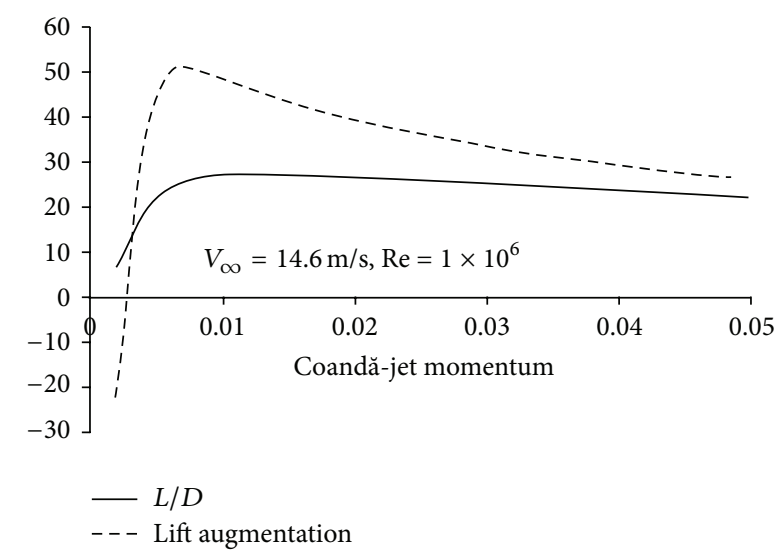

(b)

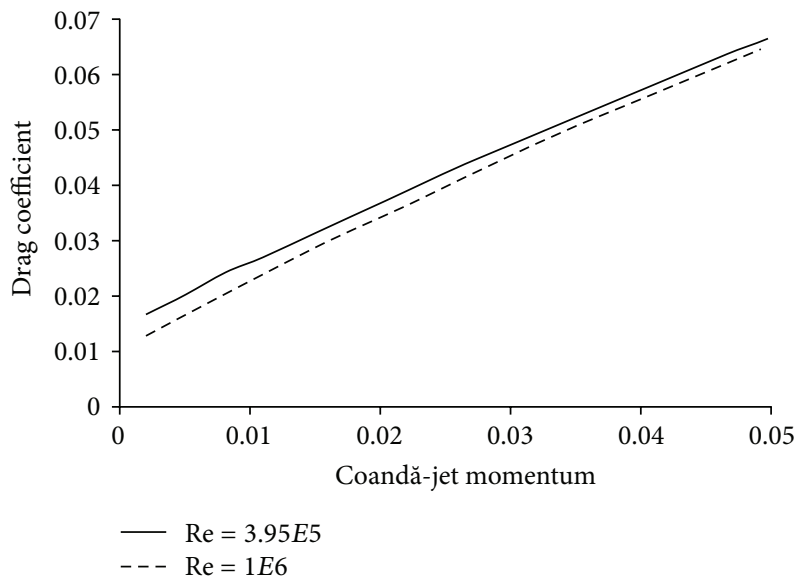

(d)

FIGURE 12: The effect of jet momentum on the $L / D$ and lift augmentation $\left(R_{\mathrm{TE}}=50 \mathrm{~mm}, t_{\text {jet }}=1 \mathrm{~mm}\right) ;(\mathrm{a}) \operatorname{Re}=3.95 \times 10^{5} ;(\mathrm{b}) \operatorname{Re}=1.0 \times 10^{6}$.

To justify the results of the present study, and to give us a physical explanation of the effect of Coandă-jet, one may attempt to carry out simple calculation using first principle and Kutta-Joukowski law for potential flow and compare the lift of the Coandă configured airfoil with the clean one obtained using CFD code. One has

$$
\begin{aligned}
& L_{\text {Coandă-jet Airfoil }} \\
& \quad=L_{\text {clean Airfoil }}+\rho V_{\infty}\left(V_{\text {Coandă-jet }} h_{\text {Coandă-jet }}\right),
\end{aligned}
$$

where $h_{\text {Coandă-jet }}$ is the moment arm of the Coandă-jet with respect to the airfoil aerodynamic center. One then may arrive at a very good conclusion on the contribution of the Coandăjet to the lift (surprisingly, using CFD results for the lift $\left(L_{\text {Coandă-jet Airfoil }}\right)$ values, the accuracy obtained by using (3) was in the order of $1.39 \%)$. However, care should be exercised to insure valid modeling for comparison.

For the three-dimensional configuration, there is a physical relationship between the Wind turbine shaft torque (which is a direct measure of the extracted shaft power) with $C_{\mu}$ and, in the actual three-dimensional case, the wind turbine rotor yaw angle $[19,20]$. From the numerical results gained thus far, it can be deduced that circulation control, which in this particular case obtained by utilizing TE Coandă-jet, can considerably increase the torque generated through the $L / D$ increase gained.

It should be noted that the results obtained in the present work is limited to two-dimensional wind turbine blade analysis, which at best can be interpreted to be valid at 0.7 blade span distance from the wind turbine rotor hub axis. The ambient air free-stream wind speed $V_{\infty}$ for the Wind turbine is different from the $V_{\infty}$ implied in the present two-dimensional parametric study, which is the resultant of the ambient-air wind speed and the rotational speed of the particular section of the rotor blade. In addition, the centrifugal effects should then be superposed to the local relative flow at the wind turbine blade airfoil cross section. The free-stream flow considered in the present two-dimensional study should be appropriately regarded as the total relative flow at the cross section analyzed, which comprises the wind free-stream velocity, the blade rotational velocity at that points and the centrifugal effect. For three-dimensional case, 3D conditions should be applied in the utilization of the CFD computational code. These factors should be considered in translating the two-dimensional study to three-dimensional cases. 


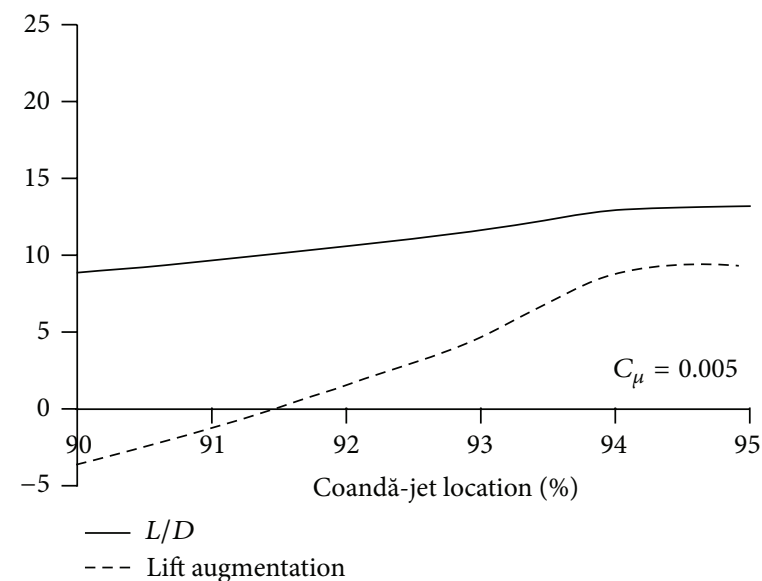

(a)
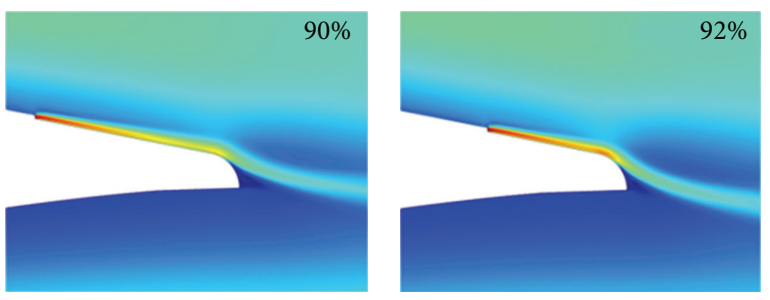

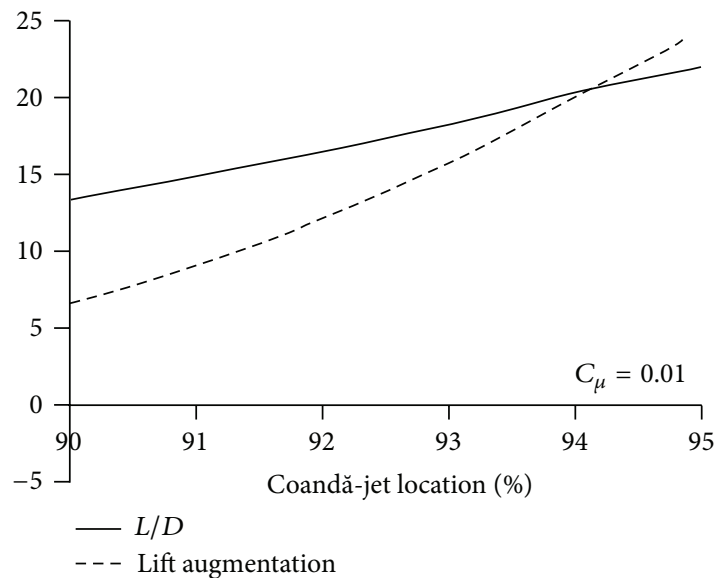

(b)
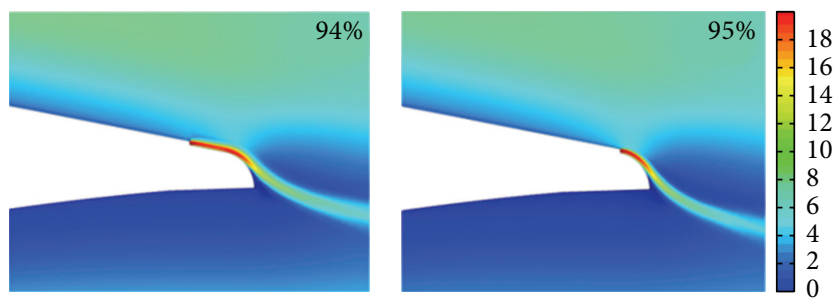

(c)

Figure 13: The effect of Coandă-jet location on the $L / D$ and lift augmentation $\left(\operatorname{Re}=1 \times 10^{6}, R_{\mathrm{TE}}=10 \mathrm{~mm}, t_{\mathrm{jet}}=1 \mathrm{~mm}\right) ;(\mathrm{a}) C_{\mu}=0.005$; $(\mathrm{b})$ $C_{\mu}=0.010 ;(\mathrm{c})$ velocity flow field for different Coandă-jet location, $C_{\mu}=0.010$.

With due considerations of the three-dimensional case, from the numerical results gained thus far, it can be deduced that circulation control, which in this particular case obtained by utilizing TE Coandă-jet, can considerably increase the torque generated through the $L / D$ increase gained.

Consequently, Coandă-jet has the potential to increase the energy output delivered by a Coandă configured Wind turbine. To this end, one may recall that the maximum power that can be delivered by a Wind turbine cannot exceed the Betz limit, which is given by

$$
P_{\text {Betz }}=\frac{8}{27} \rho A_{\text {wind turbine rotor }} V_{\infty}^{2},
$$

where $V_{\infty}$ is the wind speed.

Hence, with the introduction of Coandă-jet, using considerations reflected by (5) to derive the new Wind turbine energy output, this limit can be exceeded. Tongchitpakdee [20] has also confirmed such situation, for certain values of Coandă-jet momentum coefficient.

With regard to the design implementation of the present results and concepts, the maximum theoretical power that can be extracted from the free-stream (ambient air) in the real three-dimensional situation is given by (6). With the use of Coandă-jet, assuming the jet energy can be drawn from the inner part of the free-stream in the vicinity of the wind turbine rotor hub, the Coandă jet additional power output corresponding to the jet momentum coefficient should contribute to the increase of shaft power output given by the theoretical Betz limit. Jones and Englar studies [32] also indicated such results. With such scheme, the power required for introducing Coandă-jet can be minimized and readily be estimated from the total Coandă-jet velocity and mass flow, although the implementation required meticulous design and will be the subject of a separate study.

\section{Conclusion and Further Work}

CFD numerical experiments have been carried out to elaborate work reported earlier [53-55], with the objective to verify the favorable effects of Coandă configured airfoil for enhanced aerodynamic performance and obtain some guidelines for the critical features of Coandă configured airfoil. Care has been exercised in the choice of turbulence model and other relevant parameters commensurate with the grid fineness desired, in particular since the number of grid utilized is relatively small in view of the desktop computer utilized capabilities. Comparison of the numerical computation results for some baseline cases with experimental data under similar conditions lends support to the present computational parametric study.

CFD numerical computations for the flow field around two-dimensional airfoil S809 have been carried out with the objective to study the extent to which the introduction of Coandă-jet enhances the aerodynamic performance of the airfoil, here represented by the $L / D$ value, and leads to the following observations.

The introduction of Coandă-jet on both airfoils carried out in the present work results in enhanced $L / D$, which depends on the jet velocity. For S809 Coandă configured 
airfoil, for a certain range of the jet velocity, the increase of $L / D$ as well as the lift augmentation are monotonic. The twodimensional results show that the effects of Coandă-jet in modifying aerodynamic performance in general agree with those obtained for three-dimensional results of Tongchitpakdee et al. $[19,20]$.

Rounding-off of the TE along with the introduction of the Coandă-jet seems to be effective in increasing $L / D$ in airfoil specifically designed for Wind turbine, here exemplified by S809. Such result may be due to the relatively large TE dimension of the Wind turbine specifically designed airfoil compared to that with sharper TE. To a certain extent, smaller TE radii produced better $L / D$ than larger ones. It is also noted that, after certain value, further increase in TE radius does not give significant lift augmentation, as indicated by Figure 10(a). There is a range of effective Coandă-jet size designs, depending on their thickness. Within the limits of local boundary layer thickness, there is a certain range of effective Coandă-jet thickness. The present study indicates that the optimum jet thickness commensurate with the airfoil dimension. Care should be exercised to avoid flow separation at larger Coandă-jet thickness is dependent on the airfoil dimensions. Coandă-jet thickness and TE rounding-of $\mathrm{f}$ size, the Coandă-jet momentum needed to improve the performance (lift augmentation due to jet) should not be excessive but sufficient to delay separation until the tip of the TE (where the upper surface meets the lower one). In addition, the Coandă-jet should be placed sufficiently close to the TE to avoid premature separation.

With due considerations of prevailing three-dimensional effects, the two-dimensional numerical study can be used to direct further utilization of the CFD computational procedure for Wind turbine blade studies and their design optimization. Numerical results presented have been confined to zero angle of attack case, which has been considered to be very strategic in exhibiting the merit of Coandă-jet as lift enhancer. The numerical studies could be extended to increasing the angle of attack to obtain more comprehensive information, for which the choice of turbulence model will be more crucial.

The study also shows that the maximum total energy output of Coandă configured airfoil may exceed that predicted by Betz limit. With all the results obtained thus far, it is felt that the present work is by no means exhaustive. Other issues may still be explored, such as how could the ambient air energy input that can be drawn by the Coandă-jet configured Wind turbine either from the nacelle or elsewhere be utilized to energize the Coandă-jet and, for that matter, to lower the cutin speed of HAWT or the starting speed of VAWT.

\section{Nomenclature}

CFD: Computational fluid dynamic

CCW: Circulation control wing

$R: \quad$ Trailing edge radius $(\mathrm{mm})$

$C: \quad$ Airfoil chord length (m)

L: $\quad$ Lift force $(\mathrm{N})$

D: $\quad$ Drag force $(\mathrm{N})$

$H$ : $\quad$ Coandă-jet thickness $(\mathrm{mm})$

\author{
$L / D: \quad$ Lift over drag ratio \\ TE: Trailing edge \\ STOL: Short takeoff landing \\ $y^{+}$: Dimensionless wall distance for a \\ wall-bounded flow \\ $u_{\tau}$ : Friction velocity \\ $y: \quad$ Distance to the nearest wall \\ $v$ : Kinematic viscosity \\ $\tau_{w}: \quad$ Wall shear stress \\ $\rho: \quad$ Density \\ $\mu_{\tau}$ : Turbulent viscosity, as defined by (2) and \\ implied by context \\ HAWT: Horizontal axis wind turbine \\ M: $\quad$ Mach number \\ $\mathrm{C}_{\mu}$ : $\quad$ Turbulent model constant, as defined by (2) \\ $C_{\mu}: \quad$ Momentum coefficient \\ $\Delta C_{L} / C_{L}:$ Lift augmentation \\ $\Delta C_{L} / C_{\mu}$ : Lift augmentation due to Coandă-jet \\ MW: Megawatt \\ MWh: Megawatt hour.
}

\section{Conflict of Interests}

The authors assure that there is no conflict of interests whatsoever with any commercial products, including CFD codes, that have been utilized in the present work. Any commercial software codes that are used in the present work, such as Fluent and COMSOL, are used for the purpose of arriving at research results and have been acquired through purchase, without any vested interest whatsoever from the authors.

\section{Acknowledgments}

The present research was initiated under Universiti Putra Malaysia (UPM) Research University Grant Scheme (RUGS) no. 05-02-10-0928RU, CC-91933, and the Ministry of Higher Education Exploratory Research Grant Scheme Project Code no. 5527088. The first and corresponding author would also like to thank Universitas Al-Azhar Indonesia for the opportunity to carry out the present research at Universiti Putra Malaysia.

\section{References}

[1] J. F. Manwell, J. G. McGowan, and A. L. Rogers, Wind Energy Explained, Wiley, Amherst, Mass, USA, 1st edition, 2002.

[2] T. Ackermann and L. Söder, "Wind energy technology and current status: a review," Renewable and Sustainable Energy Reviews, vol. 4, no. 4, pp. 315-374, 2000.

[3] C. E. Lan and J. F. Campbell, "Theoretical Aerodynamics of Upper-Surface Blowing Jet-Wing Interaction," NASA TN D7936, 1975.

[4] M. J. Harris, "Investigation of the circulation control wing/upper surface blowing high-lift system on a low aspect ratio semispan model," Report DTNSRDC/ASED-81/10, David Taylor Naval Ship R\&D Center, Aviation and Surface Effects Department, Bethesda, Md, USA, 1981. 
[5] R. J. Englar, M. J. Smith, S. M. Kelley, and R. C. Rover, "Application of circulation control to advanced subsonic transport aircraft-part I: airfoil development," Journal of Aircraft, vol. 31, no. 5, pp. 1160-1168, 1994.

[6] R. J. Englar, M. J. Smith, S. M. Kelley, and R. C. Rover, "Application of circulation control to advanced subsonic transport aircraft-part II: transport application," Journal of Aircraft, vol. 31, no. 5, pp. 1169-1177, 1994.

[7] Y. G. Zhulev and S. I. Inshakov, "On the possibility of enhancing the efficiency of tangential blowing of a slit jet from an airfoil surface," Fluid Dynamics, vol. 31, no. 4, pp. 631-634, 1996.

[8] M. Gad-el-Hak, "Modern developments in flow control," Applied Mechanics Reviews, vol. 49, no. 7, pp. 365-379, 1996.

[9] R. J. Englar, "Advanced aerodynamic devices to improve the performance, economics, handling and safety of heavy vehicles," SAE Technical Paper Series, Paper no. 2001-01-2072, 2001.

[10] Y. Liu, L. N. Sankar, R. J. Englar, and K. Ahuja, "Numerical simulations of the steady and unsteady aerodynamic characteristics of a circulation control wing," in Proceedings of the 39th AIAA Aerospace Sciences Meeting, AIAA, Reno, Nev, USA, 2001.

[11] Y. Liu, Numerical simulations of the aerodynamic characteristics of circulation control wing sections [Ph.D. thesis], Georgia Institute of Technology, 2003.

[12] J. Wu, L. N. Sankar, and S. Kondor, "Numerical modeling of Coandă jet controlled nacelle configurations," in Proceedings of the 42nd AIAA Aerospace Sciences Meeting and Exhibit, pp. 2358-2366, January 2004.

[13] M. H. Shojaefard, A. R. Noorpoor, A. Avanesians, and M. Ghaffarpour, "Numerical investigation of flow control by suction and injection on a subsonic airfoil," American Journal of Applied Sciences, vol. 10, pp. 1474-1480, 2005.

[14] M. Mamou and M. Khalid, "Steady and unsteady flow simulation of a combined jet flap and Coandă jet effects on a 2D airfoil aerodynamic performance," in Proceedings of the Revue des Energies Renouvelables (CER '07), pp. 55-60, Oujda, Morocco, 2007.

[15] S. K. Sinha, "Optimizing wing lift to drag ratio enhancement with flexible-wall turbulence control," in Proceedings of the 25th AIAA Applied Aerodynamics Conference, pp. 1670-1685, June 2007.

[16] R. Radespiel, K. C. Pfingsten, and C. Jensch, "Flow analysis of augmented high-lift systems," in Hermann Schlichting-100 Years, vol. 102, pp. 168-189, Technische Universität Braunschweig, Springer, Berlin, Germany, 2009.

[17] G. Xu and L. N. Sankar, "Computational study of horizontal axis wind turbines," Journal of Solar Energy Engineering, Transactions of the ASME, vol. 122, no. 1, pp. 35-39, 2000.

[18] E. P. N. Duque, W. Johnson, C. P. van Dam, R. Cortes, and K. Yee, "Numerical predictions of wind turbine power and aerodynamic loads for the NREL phase II combined experiment rotor," in Proceedings of the 38th AIAA Aerospace Sciences Meeting, AIAA, Reno, Nev, USA, 2000.

[19] C. Tongchitpakdee, S. Benjanirat, and L. N. Sankar, "Numerical studies of the effects of active and passive circulation enhancement concepts on wind turbine performance," Journal of Solar Energy Engineering, Transactions of the ASME, vol. 128, no. 4, pp. 432-444, 2006.

[20] C. Tongchitpakdee, Computational studies of the effects of active and passive circulation enhancement concepts on wind turbine performance [Ph.D. thesis], Georgia Institute of Technology, 2007.
[21] A. Hokpunna and M. Manhart, "A large-Eddy simulation of vortex cell flow with incoming turbulent boundary layer," Engineering and Technology, vol. 32, 2007.

[22] C. L. Rumsey and P. R. Spalart, "Turbulence model behavior in low Reynolds number regions of aerodynamic flowfields," in Proceedings of the 38th AIAA Fluid Dynamics Conference and Exhibit, Seattle, Wash, USA, June 2008.

[23] F. R. Menter, "Advances in Turbulence Modelling of Unsteady Flows," Menter Shear Stress Transport Model, ANSYS, Germany, 2009, http://turbmodels.larc.nasa.gov/sst.html.

[24] L. D. Kral, "Active flow control technology," ASME Fluids Engineering Technical Brief, 2000.

[25] P. F. Zhang, B. Yan, A. B. Liu, and J. J. Wang, "Numerical simulation on plasma circulation control airfoil," AIAA Journal, vol. 48, no. 10, pp. 2213-2226, 2010.

[26] P. F. Zhang, B. Yan, and C. F. Dai, "Lift enhancement by synthetic jet circulation control," Science China, Technological Science, vol. 55, pp. 2585-2592, 2012.

[27] M. P. Patel, S. Vasudevan, R. C. Nelson, and T. C. Cork, "Plasma Aerodynamic Control Effectors for Improved Wind Turbine Performance," Orbital Research Inc., Cleveland, Ohio, USA, 2008.

[28] R. C. Nelson, T. C. Corke, H. Othman, M. P. Patel, S. Vasudevan, and T. Ng, "A smart wind turbine blade using distributed plasma actuators for improved performance," in Proceedings of the 46th AIAA Aerospace Sciences Meeting and Exhibit, Reno, Nev, USA, January 2008.

[29] G. Xu, Computational studies of horizontal axis wind turbines [Ph.D. thesis], School of Aerospace Engineering, Georgia Institute of Technology, Atlanta, Ga, USA, 2001.

[30] J. L. Tangler and D. M. Somers, "NREL Airfoil Families for HAWTs,” NREL/TP 442-7109, UC Category: 1211, DE95000267, American Wind Energy Association, 1995.

[31] G. M. Joselin Herbert, S. Iniyan, E. Sreevalsan, and S. Rajapandian, "A review of wind energy technologies," Renewable and Sustainable Energy Reviews, vol. 11, no. 6, pp. 1117-1145, 2007.

[32] G. S. Jones and R. J. Englar, "Advances in pneumatic controlled high lift systems through pulsed blowing," in Proceedings of the 21st Applied Aerodynamics Conference, AIAA, Orlando, Fla, USA, 2003.

[33] O. C. Zienkiewicz and R. L. Taylor, The Finite Element Method, Butterworth-Heinemann, 5th edition, 2000.

[34] F. H. Harlow and P. Nakayama, "Transport of turbulence energy decay rate," Report LA-3854, Los Alamos Science Laboratory, University of California, 1968.

[35] D. Kuzmin, O. Mierka, and S. Turek, "On the implementation of the k-e turbulence model in incompressible flow solvers based on a finite element discretization," International Journal of Computing Science and Mathematics, vol. 1, no. 2-4, pp. 193206, 2007.

[36] F. H. Harlow and P. Nakayama, "Turbulence transport equations," Physics of Fluids, vol. 10, no. 11, 1967.

[37] B. E. Launder, A. Morse, W. Rodi, and D. B. Spalding, "The prediction of free shear flows-a comparison of the performance of six turbulence models," in Proceedings of NASA Conference on Free Shear Flows, Langley, Va, USA, 1972, Also Imperial College Mechanical Engineering Department Report TM/TN/A/19.

[38] B. E. Launder and B. I. Sharma, "Application of the energydissipation model of turbulence to the calculation of flow near a spinning disc," Letters in Heat and Mass Transfer, vol. 1, no. 2, pp. 131-137, 1974. 
[39] W. P. Jones and B. E. Launder, "Predictions of low-Reynoldsnumber phenomena with a Z-equation model of turbulence," International Journal of Heat and Mass Transfer, vol. 16, no. 6, pp. 1119-1130, 1973.

[40] W. P. Jones and B. E. Launder, "The prediction of laminarization with a two-equation model of turbulence," International Journal of Heat and Mass Transfer, vol. 15, no. 2, pp. 301-314, 1972.

[41] J. Boussinesq, "Essai sur la théorie des eaux courantes," Mémoires Présentés par Divers Savants à l'Académie des Sciences, vol. 23, no. 1, pp. 1-680, 1877.

[42] E. Farsimadan, A study of the turbulent wake of an airfoil in an air stream with a $90^{\circ}$ curvature using hot-wire anemometry and large Eddy simulation [Ph.D. thesis], Brunel University, 2008.

[43] D. C. Wilcox, Turbulence Modeling for CFD, DCW Industries, 3rd edition, 2006.

[44] S. Benjanirat, Computational Studies of Horizontal Axis Wind Turbines in High Wind Speed Condition using Advanced Turbulence Models [Ph.D. thesis], Georgia Institute of Technology, 2006.

[45] S. M. Salim and S. C. Cheah, "Wall y+ strategy for dealing with wall-bounded turbulent flows," in Proceedings of the International Multi-Conference of Engineers and Computer Scientists (IMECS '09), vol. 2, Hong Kong, 2009.

[46] T. D. Economon and W. E. Milholen II, "Parametric Investigation of a 2-D Circulation Control Geometry, Configuration Aerodynamics Branch Research and Technology Directorate," 2008.

[47] H. Grotjans and F. Menter, "Wall functions for general application CFD codes," in Proceedings of the 4th Computational Fluid Dynamics Conference (ECCOMAS '98), pp. 1112-1117, John Wiley \& Sons, 1998.

[48] "COMSOL, 4.2. CFD Module User's Guide, COMSOL, Inc. 1," New England Executive Park, Burlington, Mass, USA, 2011.

[49] R. Howell, N. Qin, J. Edwards, and N. Durrani, "Wind tunnel and numerical study of a small vertical axis wind turbine," Renewable Energy, vol. 35, no. 2, pp. 412-422, 2010.

[50] D. M. Somers, Design and Experimental Results for the S809 Airfoil, Airfoils, State College, Pa, USA, 1989.

[51] E. O. Rogers, "Development of Compressible Flow Similarity Concepts for Circulation Control Airfoils," AIAA-87-0153, 1987.

[52] J. Abramson and E. O. Rogers, "High-speed characteristics of circulation control airfoils," AIAA-83-0265, 1988.

[53] M. F. Abdul Hamid, H. Djojodihardjo, S. Suzuki, and F. Mustapha, "Numerical assessment of Coandă effect as airfoil lift enhancer in wind-turbine configuration," in Proceedings of the Regional Conference on Mechanical and Aerospace Technology, paper RCMEAE-131, Bali, Indonesia, 2010.

[54] H. Djojodihardjo and M. F. Abdul Hamid, "Review and numerical analysis of Coandă effect circulation control for wind turbine application considerations," in Proceedings of the Conference on Aerospace and Mechanical Engineering, World Engineering Congress, Kuching, Sarawak, Malaysia, 2010.

[55] H. Djojodihardjo, M. F. Abdul Hamid, S. Basri, F. I. Romli, and D. L. A. Abdul Majid, "Numerical simulation and analysis of Coandă effect circulation control for wind-turbine application considerations," IIUM Engineering Journal, 2011. 


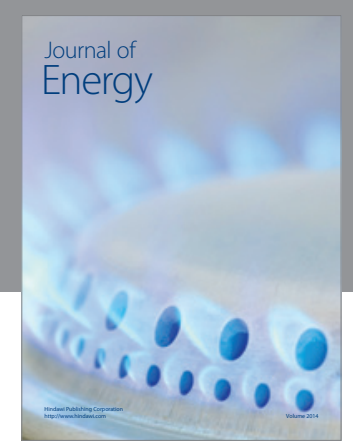

Journal of

Industrial Engineering
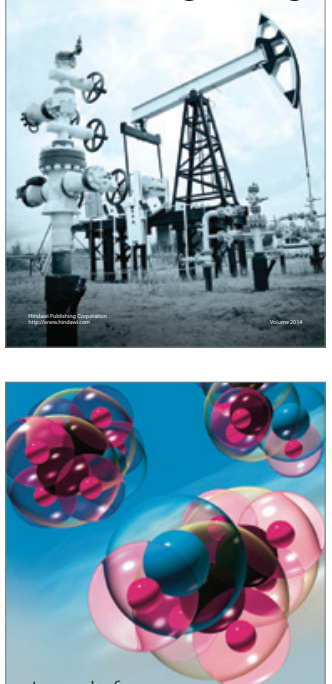

Fuels
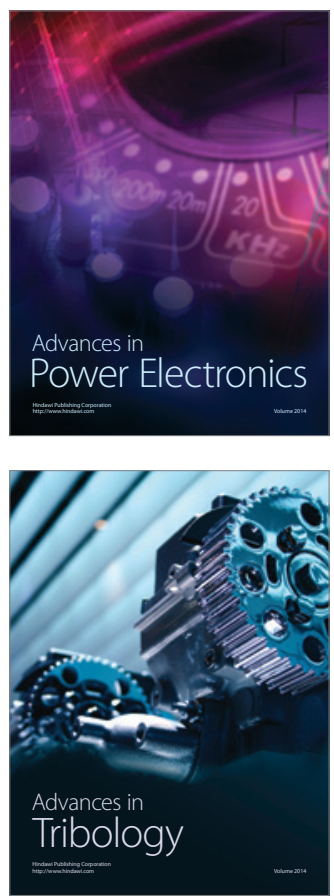

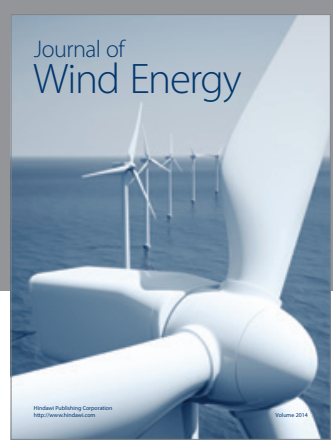

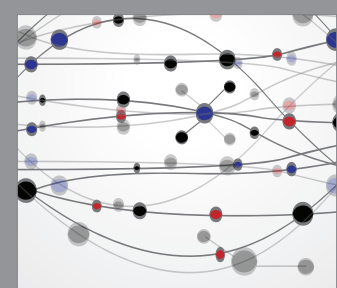

The Scientific World Journal

Submit your manuscripts at http://www.hindawi.com

Journal of

Structures
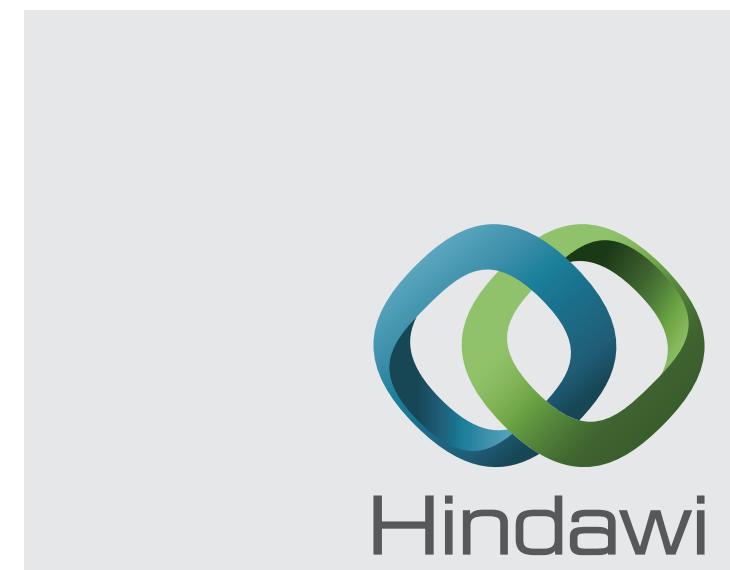

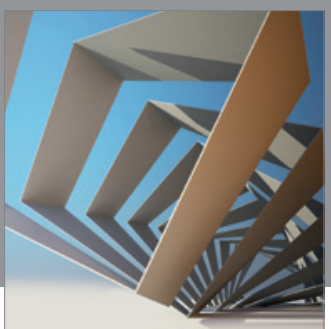

Rotating

Machinery
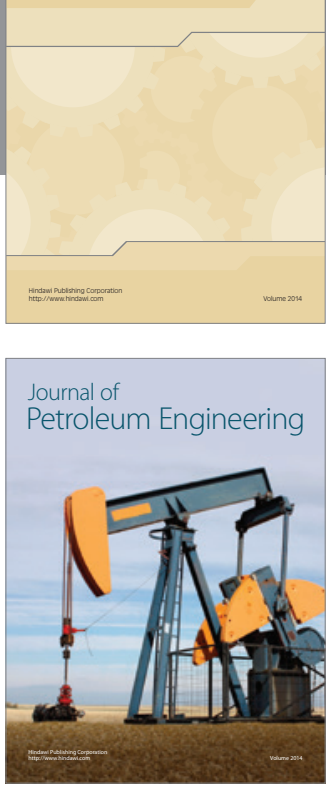

Journal of

Solar Energy
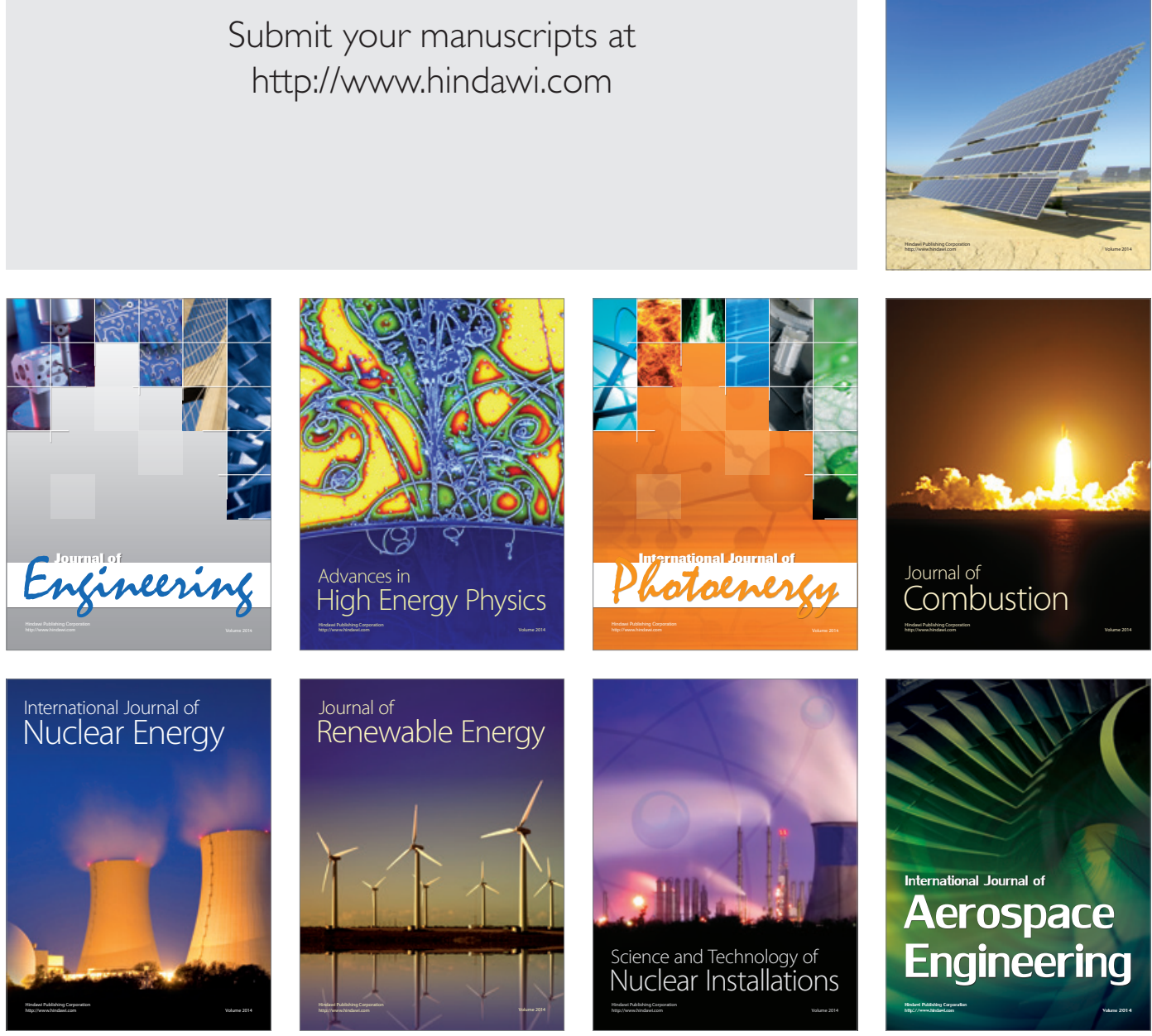